\title{
Stylolite-controlled diagenesis of a mudstone carbonate reservoir: a case study from the Zechstein_2_Carbonate (Central European Basin, NW Germany)
}

Humphrey, E. ${ }^{a}$, Gomez-Rivas E. ${ }^{\mathrm{a}, \mathrm{b}}$, Koehn, D. ${ }^{\mathrm{c}}$, Bons P.D. ${ }^{\mathrm{d}, \mathrm{e}}$, Neilson, J. ${ }^{\mathrm{a}}$, Martín-Martín J.D. ${ }^{\mathrm{b}}$ and Schoenherr, J. ${ }^{\mathrm{f}}$

(a) School of Geosciences, King's College, University of Aberdeen, AB24 3UE Aberdeen, United Kingdom

(b) Departament de Mineralogia, Petrologia i Geologia Aplicada, Facultat de Ciències de la Terra, Universitat de Barcelona (UB), Martí i Franquès s/n, 08028 Barcelona, Spain

(c) School of Geographical and Earth Sciences, University of Glasgow, Lilybank Gardens, G12 8QQ Glasgow, Scotland, UK

(d) China University of Geosciences (Beijing), Xueyuan Road 29, Haidian district, 100083 Beijing, China

(e) Department of Geosciences, Eberhard Karls University of Tübingen, Wilhelmstr. 56, 72074 Tübingen, Germany

(f) ExxonMobil Production Deutschland GmbH, Riethorst 12, 30659 Hannover, Germany

Corresponding author: Humphrey, E.: Department of Geology and Petroleum Geology, School of Geosciences, University of Aberdeen, Meston Building, King's College, Aberdeen AB24 3UE, Scotland, United Kingdom; + 44 (0) 1224 273915; e.humphrey@abdn.ac.uk

\begin{abstract}
Stylolites are rough dissolution surfaces that form due to intergranular pressure-solution resulting from burial compaction or tectonic stress. Despite being ubiquitous in most carbonate rocks, their potential impact on structural diagenesis and fluid flow remains unclear. The Zechstein 2 Carbonate (Ca2) is a diagenetically complex reservoir in the Southern Permian Basin and represents one of the most prolific gas reservoirs in NW Germany. This investigation focuses on evaluating the relationship between stylolites, fractures/veins and their subsequent influence on the spatial variations in reservoir quality. We utilise drill core samples to carry out a combined analysis of cross-cutting relationships between different structures and diagenetic products. We therefore use a combination of petrography and statistical analyses on stylolite networks, focusing on their occurrence, morphology and sealing capacity. In the study area, the Ca2 carbonate mudstone was deposited in a slope environment and dolomitised under shallow burial conditions, followed by bedding-parallel stylolitisation during burial. Results indicate that calcium-rich fluids percolated from neighbouring evaporite units causing widespread calcitisation within the more distal environments of deposition. Some stylolites locally acted as barriers to affect the migration of the calcitising fluids, resulting in a macroscopic diagenetic stratification of relatively porous dolomite and areas of calcitised dolomite with lower porosity. However, pressure-solution continued during burial and bedding-parallel stylolites also appear postdating calcitisation. During inversion, horizontal stylolites were reopened to act as conduits to enable fluid migration that precipitated metal sulphides. This indicates that stylolites acted as both barriers and conduits for fluid flow depending on variations of the overburden pressure and regional stress regime. Stylolites present a range of sealing capacities between 63-89\%, depending on their morphology, and can result in partial leakage and subsequent invasive calcitisation in their vicinity. This study highlights the importance of understanding the impact of stylolites on structural diagenesis and spatial variations in petrophysical rock properties that determine reservoir quality.
\end{abstract}

Keywords: Stylolites, Calcitisation, Dolomitisation, Carbonate Reservoir Quality, Zechstein Ca2

This manuscript is published in the journal Marine and Petroleum Geology (2019), vol. 109, 88-107. DOI: https://doi.org/10.1016/j.marpetgeo.2019.05.040. This is an author version of the article. For the final copy-edited version, please visit:

https://www.sciencedirect.com/science/article/pii/S0264817219302454 


\section{Introduction}

Reservoir quality of carbonate rocks is generally very challenging to predict due to the combination of: (i) highly heterogeneous environments of deposition that result in strong lateral and vertical variations of depositional facies, (ii) diagenetic overprints due to cementation, dissolution, compaction and mineral replacement, and (iii) the presence of rock deformation structures of various scales, such as faults, fractures and stylolites. The last decades have seen a significant increase in the number of studies assessing the influence of tectonic structures on fluid flow in carbonates (e.g., Agar and Geiger, 2015), including publications on structural diagenesis that focus on the complex feedback relationships between deformational structures and chemical changes in sediments and rocks (Laubach et al., 2010; Ortega et al., 2010; Giorgioni et al., 2016). Most studies in structural diagenesis have focused on the interplay between stress, fluid flow, fracture formation and mineral precipitation, and how these interactions control the evolution of permeability and reservoir quality (e.g., Gale et al. 2005). Despite the ubiquitous presence of pressure-solution structures (i.e., stylolites) in most carbonate units, very few studies have analysed their impact on the diagenetic and petrophysical evolution of the rock. However, understanding how stylolites influence and interact with other structures (such as fractures, veins and other stylolites) and diagenetic products (e.g., cements, dissolution vugs or replaced mineral phases) is key for accurately predicting fluid flow (Koepnick, 1988; Paganoni et al., 2016; Bruna et al. 2018; Ehrenberg, 2018; Heap et al. 2018; Morad et al., 2018).

Stylolites are the result of intergranular pressure solution producing irregular dissolution seams characterised by multi-scale roughness (Koehn et al. 2007; Ebner et al. 2010a, Toussaint et al., 2018). Dissolution seams can form laterally extensive planar drapes associated with strain localisation (Heap et al. 2014), and commonly host low-solubility or insoluble material such as clay, mica, oxides, etc. (Nelson, 1981; Ben-Itzhak et al., 2014). Bedding-parallel stylolites are prone to develop in rocks during compaction associated with the weight of the overburden, while tectonic stylolites form as a consequence of tectonic stresses and can therefore be found in variable orientations with respect to bedding (Koehn et al., 2016a). Due to their solubility and fast kinetics, carbonates are highly affected by pressure-solution, although stylolites are also common in sandstones (e.g., Baron and Parnell, 2007) and evaporites (e.g., Bäuerle et al., 2000), among other rocks.

The influence of stylolites on diagenesis is nowadays a controversial topic since it is still debated to what extent stylolites do influence fluid flow. Whilst stylolites can be used to determine the orientation and magnitude of principle compressive stress on a rock (Koehn et al., 2012), their dynamic behaviour has varied impacts on reservoir quality. Early studies suggested a polarised behaviour where stylolites either reduce permeability acting as baffles to fluid flow (e.g., Burgess \& Peter, 1985; Dawson, 1998; Ben-Itzhak et al., 2014) or become conduits for fluids by increasing permeability parallel to them, as observed in some carbonate reservoirs (e.g., Braithwaite, 1989; Baron and Parnell, 2007). Alternatively, Ehrenberg (2004) and Ehrenberg et al. (2006) relate stylolite development to calcite cementation where increasing stylolite frequency causes cementation and a subsequent reduction in local porosity. More recent studies featuring both examples of stylolite-associated petrophysical alterations suggest that their behaviour can change over time depending on the evolution of the physical conditions that the rocks are subjected to (Martín-Martín et al., 2017), the evolving heterogeneity of stylolite morphology (Koehn and Beaudoin, 2017) and the mineral composition of the host rocks (Morad et al., 2018). Additionally, the dynamic interaction between stylolites and diagenetic fluids can affect paleo-fluid pathways to control diagenetic 
alteration geometries (Gomez-Rivas et al., 2015). Some authors claim that stylolites may possess little or no influence on reservoir quality and permeability (Baud et al., 2014; Heap et al., 2014), since their laterally discontinuous morphology prevents them from acting as regional baffles and therefore only affect petrophysical properties locally. However, laterally continuous stylolite seams and networks do exist in hydrocarbon-bearing limestones, subdividing reservoir intervals through their morphology and petrophysical responses (Hassan and Wada, 1981; Ehrenberg et al., 2016). Stylolite networks and their influence on reservoir heterogeneity can also ultimately impact well placement and recovery efficiency (Alyan et al., 2015; Al-amrie et al., 2012). The systematic study of the interaction between stylolites, fracturing and diagenetic products is a potential way of improving our knowledge of how pressure solution seams influence fluid flow and the transport properties of rocks.

The above shows that it is still unclear if, how, when and where stylolites affect reservoir properties and their dynamic behaviour during production. The Zechstein 2 Carbonate (also known as the $\mathrm{Ca} 2$ or Stassfurt carbonate) unit of the German Lower Saxony Basin, for which many well cores are available for study, provides an excellent opportunity to improve our knowledge of the interplay between stylolites, fractures, veins and a variety of diagenetic products (Strohmenger and Strauss, 1996; Karnin et al., 1992; Reijers, 2012; Biehl et al., 2016; Becker et al., 2018; Becker et al., 2019). This unit, which formed during the second Zechstein cycle in the Late Permian, represents one of Germany's most prolific gas reservoirs in the Southern Permian Basin due to its thick under- and overlying seal and regional extent (Strohmenger et al. 1996). The Ca2 carbonate is an ideal rock to study the interplay between stylolites and other structures and diagenetic products, as multiple important diagenetic overprinting relationships can be observed. The study host rock is relatively homogeneous from a depositional point of view, therefore reducing the uncertainties associated with depositional heterogeneity when collecting data and doing interpretations.

This study focuses on understanding the impacts of stylolitisation on reservoir heterogeneity within the $\mathrm{Ca} 2$ unit, and how the evolution of stylolites has affected other structures and diagenetic products. We have analysed a series of reservoir drill core, in order to (i) characterise stylolites, veins and diagenetic products, (ii) determine the paragenetic and structural diagenetic evolution of the reservoir, (iii) estimate the statistical properties of stylolite networks, paying special attention to stylolite morphologies and their potential influence on local permeability.

\section{Geological Setting}

The Central European Basin (CEB) (for abbreviations used in the manuscript see Table 1) is extensive across central NW Europe, spanning Poland to the southern North Sea in a NWSE orientation (Maystrenko et al., 2008). Located on the central southern margin of the CEB is the Lower Saxony Basin (LSB) (Mazur \& Scheck-Wenderoth, 2005), which is bound by the Pompeckj Block (PB) to the north (South of Bremen, NW Germany) (Fig. 1). The LSB and $\mathrm{PB}$ are composed of a succession of thick Late Carboniferous, Permian, Triassic and Early Jurassic sediments overlain by Albian rocks (Betz et al. 1987).

Strohmenger et al. (1996) identified eight sequence stratigraphic cycles that were further divided into major depositional facies and subfacies throughout the Permian in the PB and LSB. Seismic modelling and well interpretations by the same authors provided estimates of the regional distribution of depositional environments. According to these, the $\mathrm{Ca} 2$ is constituted by 10-250 $\mathrm{m}$ thick slope deposits that form an E-W belt from the Netherlands to 
West Poland, with thicker deposits occurring in Western and Central Germany (Strohmenger et al., 1996).

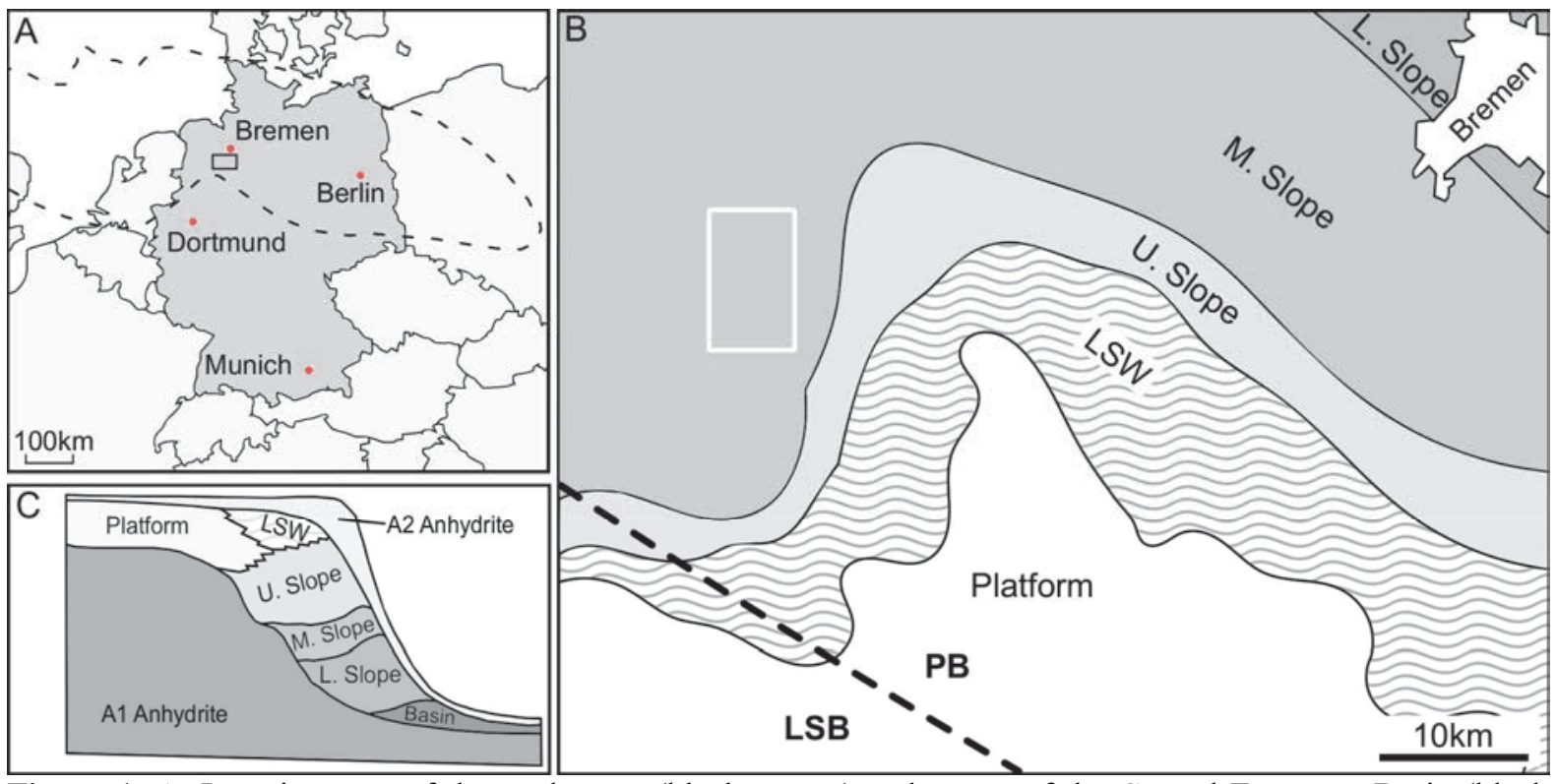

Figure 1. A. Location map of the study area (black square) and extent of the Central European Basin (black dashed line). B. Location and facies map of the study area in relation to Bremen and the boundary between the Pompeckj Block (PB) and Lower Saxony Basin (LSB) (modified from Schoenherr et al., 2014). Approximate location of wells is highlighted (white square). C. Ca2 depositional facies and distribution on the platform and slope (modified from Strohmenger et al., 1996).

The study area is situated on the middle slope facies of the Ca2 (Fig. 1c). The landward facies represent protected lagoons and reef build-ups within a restricted subtidal environment. Facies in the fair-weather wave-base form grainy shoals and ooid bars (Strohmenger et al., 1996). Middle-slope facies are classified by Strohmenger et al. (1996) as regularly-spaced, mm-bedded mudstones with micro-stylolitic overprinting, deposited below the storm wavebase. Slope carbonate mudstones underwent dolomitisation at near-surface conditions through seepage-reflux (Warren, 2000). Dolomitised carbonate mudstones on the middle slope contain organic matter with total organic carbon contents up to $0.8 \%$ (Hammes et al., 2013). Ca2 slope deposits in this area are characterised by various structures and diagenetic products, including bedding-parallel (i.e., sedimentary) stylolites, tectonic stylolites, dissolution vugs, fractures, veins, cements and replaced mineral phases (Fig. 2). Petmecky et al. (1999) used vitrinite reflectance data to derive maturation and subsidence histories of the $\mathrm{Ca} 2$ unit within the LSB and the PB. The subsidence history of the LSB was recently refined by Duschl et al. (2016) using fluid inclusions, which also provided information on the characterisation and evolution of paleo-fluid and gas systems in the geological record. The $\mathrm{Ca} 2$ unit is stratigraphically sandwiched between the underlying A1 Werra Anhydrite and the overlying A2 Basal Anhydrite (Richter-Bernburg, 1955; Strohmenger et al., 1996; Leyrer et al., 1999 ).

Both the LSB and the PB have a similar early geological history that includes PermoTriassic rifting leading to the development of multiple N-S trending grabens (Lohr et al., 2007; Scheck-Wenderoth et al., 2008; Bruns et al., 2013), especially in the PB. Opposite structural regimes between the LSB and PB commenced in the Late Cretaceous, when the PB was subjected to uplift and up to 3,000 $\mathrm{m}$ of erosion during Kimmeridgian inversion (Bruns et al., 2013). Late Cretaceous inversion resulted in the reactivation of N-S graben faults in the 
PB that caused rapid subsidence, whilst fault reactivation on the LSB margins caused sedimentary fill to be thrusted onto the PB (Betz et al., 1987).

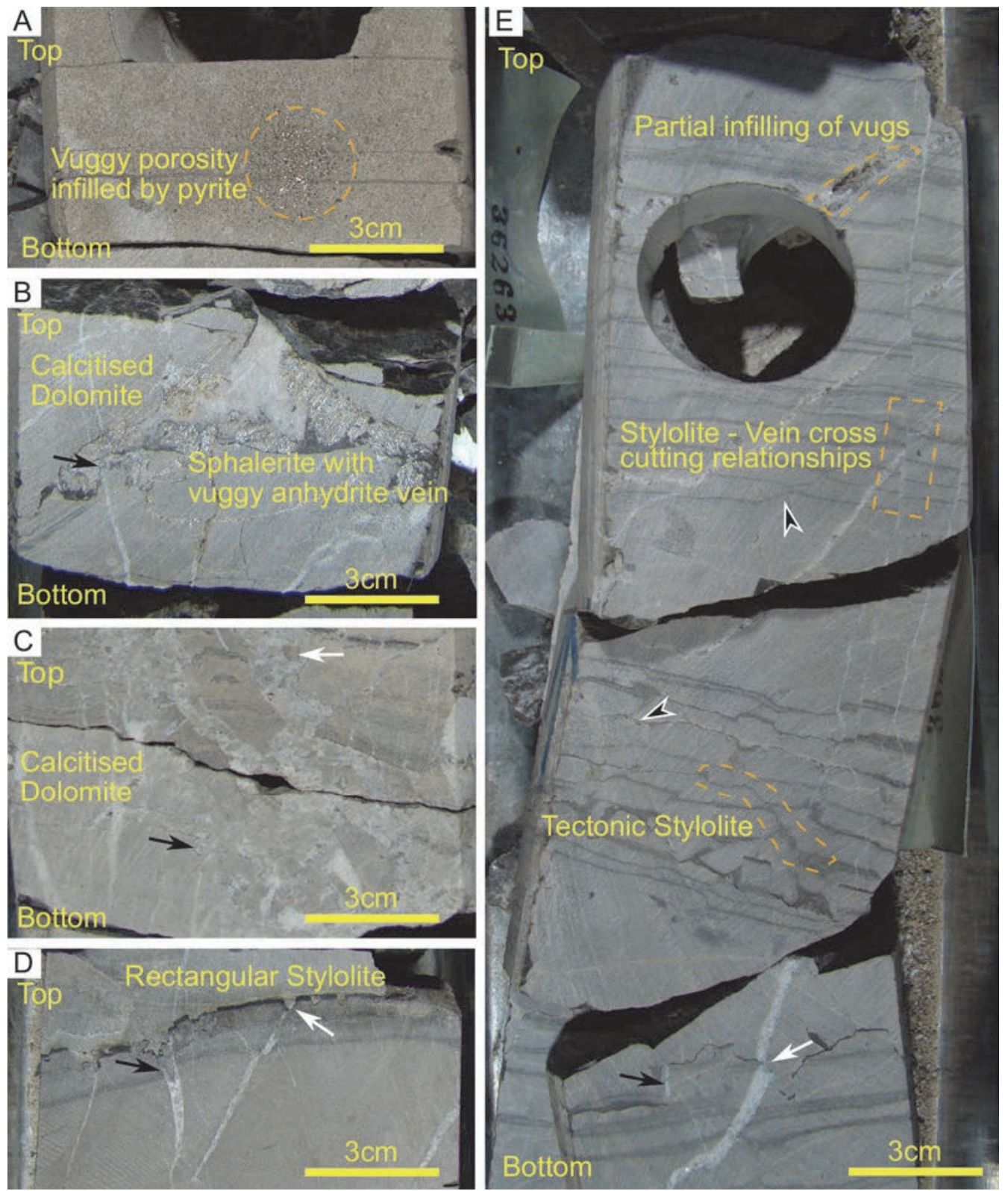

Figure 2. Overview of structural and diagenetic features from Zechstein $\mathrm{Ca} 2$ drill core photographs. A. Dolomite matrix 1 with pyrite. B. Metal sulphide and anhydrite precipitation in calcitised dolomite. C. Brecciated partially calcitised dolomite with calcite veins (white arrow) and minor stylolite interactions (black arrow). D. Rectangular layer type stylolite, as defined by Koehn et al. (2016) with calcite tension gashes (black arrow) and earlier calcite vein cementation (white arrow) in partially calcitised dolomite. E. Calcitised dolomite with wave-like type stylolitisation (black \& white arrows), vein emplacement and dissolution vugs. Beddingparallel stylolites predate or are syngenetic with calcite vein cementation (white arrow) whilst calcite later fills fractures associated with stylolitisation (black arrow).

Diagenesis of the $\mathrm{Ca} 2$ unit has recently become an area of interest (Schoenherr et al., 2018; Biehl et al., 2016). Previous studies remained limited to facies characterisation by Strohmenger et al. (1996) that were incorporated with diagenetic observations to understand environmental variations in diagenesis. Biehl et al. (2016) investigated the effects of hydrothermal dolomitisation and thermochemical sulphate reduction on secondary porosity generation within the LSB, triggered by influxes of diagenetic fluids from surrounding 
Table 1. Manuscript abbreviations and definitions listed in order of appearance.

\begin{tabular}{|c|c|}
\hline Term & Abbreviation \\
\hline Zechstein 2 Carbonate, Stassfurt Carbonate & $\mathrm{Ca} 2$ \\
\hline Central European Basin & CEB \\
\hline Lower Saxony Basin & LSB \\
\hline Pompeckj Block & PB \\
\hline $\begin{array}{l}\text { Estimated top depth of an unlabelled drill core } \\
\text { (in meters) }\end{array}$ & $D_{B}(n)$ \\
\hline $\begin{array}{l}\text { Last labelled top depth above an interpolated } \\
\text { core (in meters) }\end{array}$ & $D_{0}$ \\
\hline Length of an unlabelled interval (in meters) & $L$ \\
\hline $\begin{array}{l}\text { Number of core boxes within an unlabelled } \\
\text { interval }\end{array}$ & $N_{t}$ \\
\hline Core box number within an unlabelled interval & $n$ \\
\hline Stylolite density per core box & $V(\mathrm{n} / \mathrm{m})$ \\
\hline $\begin{array}{l}\text { Proportion of measurable rock section inside a } \\
\text { core box divided by the total length of } \\
\text { measurable rock within a core box }\end{array}$ & $W_{p}$ \\
\hline $\begin{array}{l}\text { Proportion of stylolites per measurable section } \\
\text { of rock }\end{array}$ & $V_{p}$ \\
\hline Percentage abundance of veins per core box & $V(\%)$ \\
\hline $\begin{array}{l}\text { field emission gun high resolution scanning } \\
\text { electron microscopy }\end{array}$ & FEGSEM \\
\hline Dolomite Matrix 1 & DM1 \\
\hline Calcite Matrix 1 & CM1 \\
\hline Calcite Cement 1 & CC1 \\
\hline Calcite Cement Group 2-5 & CC2-5 \\
\hline Ferroan Dolomite & FD \\
\hline Metal Sulphides & MS \\
\hline Anhydrite Cement 1 & AC1 \\
\hline Anhydrite Cement 2 & AC2 \\
\hline Calcite Cement 6 & $\mathrm{CC} 6$ \\
\hline $\begin{array}{l}\text { Back Scattered Electron Microscopy - } \\
\text { Cathodoluminescence }\end{array}$ & BSEM-CL \\
\hline $\begin{array}{l}\text { Back Scattered Electron Microscopy - Energy } \\
\text { Dispersive X-ray }\end{array}$ & BSEM-EDAX \\
\hline
\end{tabular}

anhydrite units that migrated into the Ca2 via proximal faulting. Whilst Biehl et al. (2016) identified diagenetic events relative to broad-scale burial conditions, Duschl et al. (2016) used fluid inclusion analysis to identify both the composition and timings of diagenetic fluid influx and gas creation within the LSB. Although most studies of the $\mathrm{Ca} 2$ unit are from the LSB, this study uses samples derived from a different tectono-sedimentary unit on the adjacent PB. This contribution provides new insights into the differences in diagenetic parageneses of the $\mathrm{Ca} 2$ relative to the $\mathrm{LSB}$, requiring a comparison with the abovementioned studies of the LSB to understand the spatial variation in the diagenesis of the Ca2. The influx of calcitising fluids into the $\mathrm{Ca} 2$ after dolomitisation caused widespread calcitisation, which had significant impact on influencing reservoir quality (Schoenherr et al., 2018). Hallenberger et al. (2018) recently focused on unravelling the origin of these calcitising fluids and estimated mass balance constraints, determining that calcitising fluid generated during gypsum - anhydrite dehydration would only account for $<1 \%$ of slope calcitisation in the $\mathrm{Ca} 2$. Schoenherr et al. (2018) indicates that pressure solution of the surrounding anhydrite beds is likely to be the dominant source of calcitising fluids. 


\section{Methodology}

This study combines visual analyses of cut drill core photos alongside optical and electronic microscopy of host rocks, cements and mineral phases from five wells in the PB.

\subsection{Visual analysis of core photographs}

Drill core was provided by ExxonMobil Production Deutschland GmbH from five wells, labelled from A to E, within the Zechstein $\mathrm{Ca} 2$ carbonate unit at depths between 3,890-4,070 $\mathrm{m}$ in the PB. Longitudinal sections of drill core were photographed with an average of six photos per core box (which contains approximately one metre of core). Photographs were measured using PixelStick ${ }^{\mathrm{TM}}$, a software for advanced manipulation of images, in order to quantify the spatial distribution of structures and their relative occurrence. Core was visually analysed using the scanline sampling method (Zeeb et al., 2013) to identify structures and diagenetic products, with a single scanline parallel to the long axis of core cylinders. A problem with the available drill core is that $1 \mathrm{~m}$ long boxes were grouped in intervals of up to $18.2 \mathrm{~m}$. Depths within such intervals therefore had to be estimated from the known depths of the beginning and end of the intervals. We used Eqn. 1:

$$
D_{B}(n)=D_{0}+\left(L / N_{t}\right) *(n-1)
$$

where $D_{B}(n)$ is the estimated top depth of an unlabelled drill core (in meters), $D_{0}$ is the last labelled top depth above the interpolated core (in meters), $L$ is the length of an unlabelled interval (in meters), $N_{t}$ is the number of core boxes within the unlabelled interval and $n$ is the core box number within the unlabelled interval. This method provided depth constraints for all measurements used to create structural logs and whilst accuracy was improved, uncertainty remains in core sections with large unlabelled intervals.

The relative timing of structures and formation of diagenetic products was determined from core photographs of all wells by recording cross-cutting relationships. Recorded crosscutting relationships between structural features were measured in the form of a frequency table to understand the relative timings of formation of the structures. Cross-cutting relationships were defined as either being 'cut' or 'cut by' another structure, where the interaction between two structures was defined as a single cross-cutting event (Fig. 2). Key structural features were bedding-parallel stylolites, tectonic stylolites and three subclasses of veins used in previous Ca2 core studies by Gast (2014), namely vuggy, intermediate and fracture veins. Vuggy veins describe vein morphologies that have a spongy appearance and have irregularly shaped walls, whilst fracture veins have sharp linear walls between the vein and host rock and intermediate veins share similarities with both end members (Fig. 4). Stylolite density was recorded in each measurable section of core in order to quantify distribution patterns and relationships. Stylolite density $(V)$ is defined as the number of stylolites per meter of core (with unit $\mathrm{m}^{-1}$ ) and was determined from multiple sections (photographs) within a core box.

Stylolite density was calculated by dividing the sum of bedding-parallel stylolites with the core length, and weighted per interval using Eqn. 2:

$$
V=\Sigma\left(w_{p} * v_{p}\right)
$$


where $V(\mathrm{n} / \mathrm{m})$ is the stylolite density per core box, $w_{p}$ is the proportion of measurable rock section inside the core box divided by the total length of measurable rock within the core box and $v_{p}$ is the proportion of stylolites per measurable section of rock. Stylolite measurements were combined to produce cumulative distribution graphs that were fitted with three common distributions (Zeeb et al., 2013): power-law, exponential and log-normal. Vein abundance measurements were calculated in the same way as stylolite density (eqn. 2), where $V(\%)$ is the percentage abundance of veins per core box, $w_{p}$ is the proportion of measurable rock section inside the core box divided by the total length of measurable rock within the core box and $v_{p}$ is the proportion of veins per measurable section of rock.
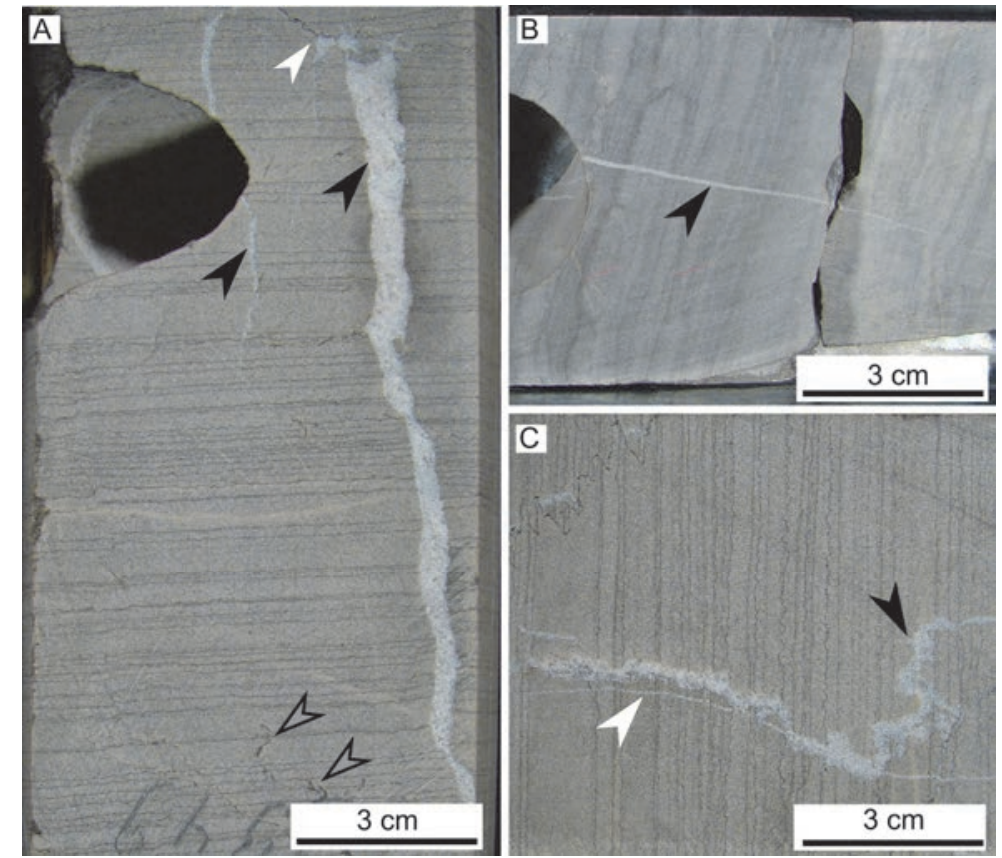

Figure 4. Core photographs of vein subclasses in calcitised dolomite. A. Intermediate vein (black arrows) being cross-cut by a bedding-parallel stylolite (white arrow), with tectonic stylolites cross-cutting bedding-parallel stylolites (grey arrows with black outline). B. Fracture vein (black arrow). C. Vuggy vein (black arrow) which is cross-cut by a fracture vein (white arrow).

Bedding-parallel stylolite spacing measurements were collected from each drill core photo, where the spacing between bedding-parallel stylolites was determined by measuring the distance between the horizontal middle of two neighbouring stylolites. A Terzaghi correction (Terzaghi, 1965) was applied when stylolites appeared orientated $>10^{\circ}$ relative to the drill core, assumed to be taken from vertical wells without any offset, to obtain the true spacing before layer tilting. Stylolite tooth amplitudes were collected in a similar manner, by measuring the distance between the top and bottom of teeth in the middle of the core. Only stylolites that were laterally continuous in core photos and above ten pixels were measured (Fig. 3). Stylolite spacing and teeth amplitudes were measured to analyse morphological trends and the 'fit' of recorded data with common distributions: exponential, log-normal and power-law. One hundred spacing measurements were taken per well, whereas two hundred measurements were taken per well for amplitude. Graphs for each distribution were created and analysed to find the most representative distribution model. Variable bin sizes were used to ensure that all bins have a minimum number of data points. 


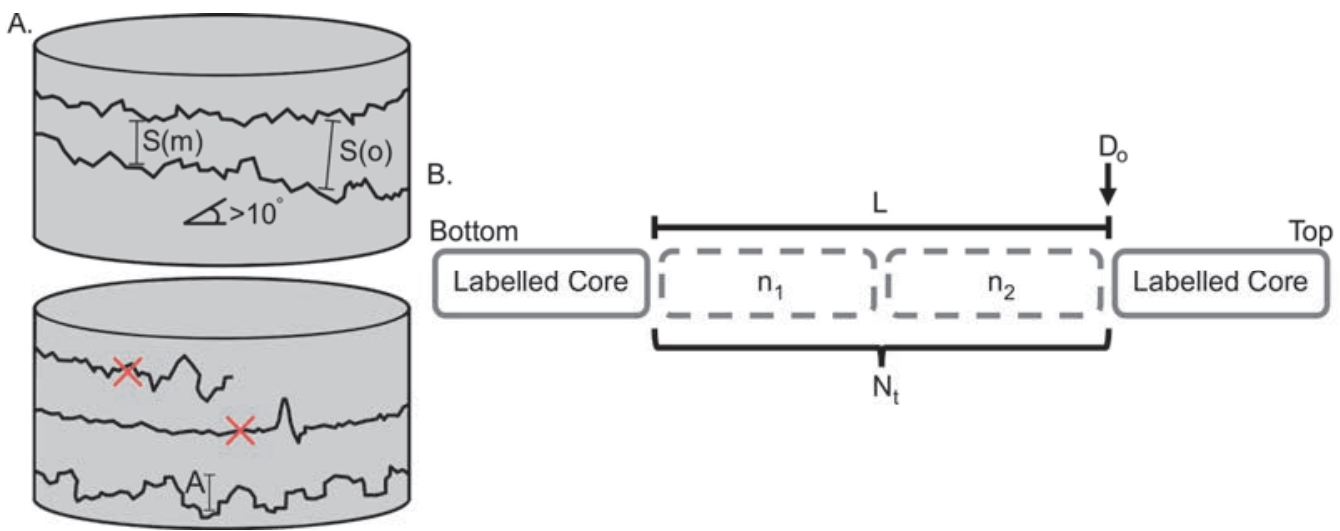

Figure 3. A. Schematic diagram illustrating the measurement criteria for stylolite spacing and teeth amplitudes; Stylolites with an angle deviating more than $10^{\circ}$ were corrected using the Terzaghi correction method (Terzaghi, 1965). Measurements were not collected between stylolites with missing rock material. $\left(S_{0}=\right.$ Original Spacing, $S_{m}=$ Measured Spacing). Teeth amplitudes $(A)$ were based on the maximum teeth amplitude; stylolites with a teeth amplitude $<10$ pixels were not measured. B. Schematic diagram of depth interpolation technique used for unlabelled core boxes where $\mathrm{D}_{0}$ is the last known top core depth, $\mathrm{L}$ is the total length of unlabelled core, $n_{\mathrm{x}}$ is the core box number and $\mathrm{N}_{\mathrm{t}}$ is the total number of unlabelled core boxes.

Stylolites were also evaluated for their sealing capacity (Fig. 5), defined as the ability to impede fluid flow. Samples were collected and classified using the scheme by Koehn et al. (2016a). Each stylolite was measured in order to find the total length cemented by insoluble material relative to the total stylolite length. Insoluble material of any thickness was considered a baffle for fluids. As measurements were collected from core photographs the sealing capacity of stylolites could only be observed in 2D, and therefore cannot not be considered fully representative of the 3D distribution of sealing material.
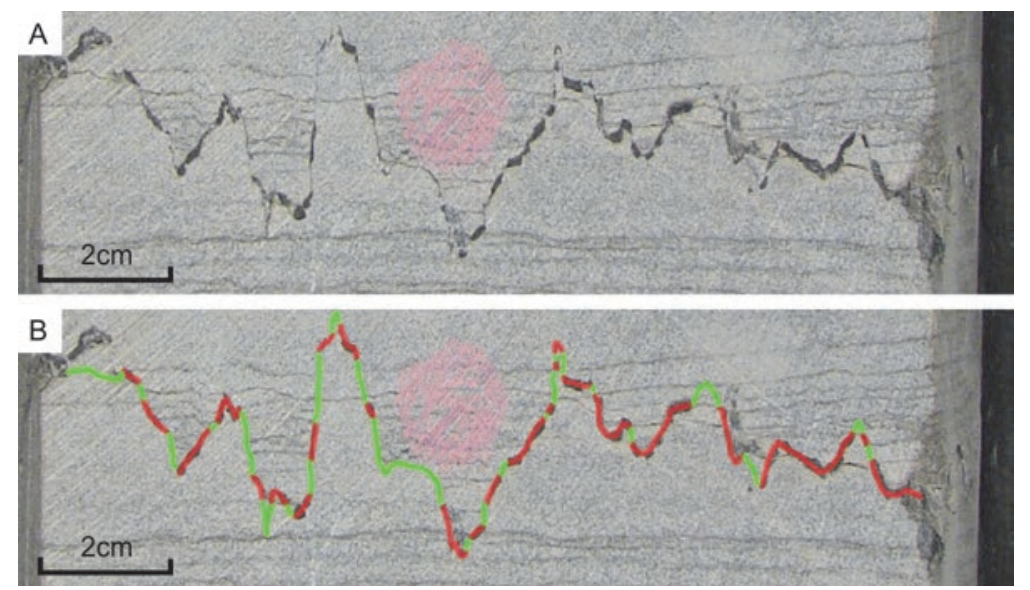

Figure 5. Diagram representing the methodology for calculating stylolite sealing capacity. A. Original stylolite without interpretation. B. Stylolite sealing (red) and non-sealing (green) sections measured along the total length of the stylolite to provide a sealing capacity (\%). Stylolites are classed as sealing depending on the thickness of insoluble material visible from core box photographs.

\subsection{Petrographic Analysis}

Twenty-seven thin sections representing the five studied wells were prepared from selected core samples for petrographic analysis. The analyses were performed in a Meiji Techno MT9000 standard optical microscope with an INFINITY-1 camera, in both plane and cross-polarised light. Six uncoated thin sections were examined using cold cathode microscopy whilst five thin sections were further selected to be polished and carbon coated for detailed textural analysis using field emission gun high resolution scanning electron 
microscopy (FEGSEM) and cathodoluminescence imaging, with a Technosyn cathodoluminescence microscope and Carl Zeiss Gemini SEM 300 microscope respectively. Textural analysis on five additional samples was carried out using scanning electron microscopy with an ISI ABT-55 microscope. Both dolomite and calcitised dolomite were detected based on crystal texture and interference colour in cross-polarised light using standard optical microscopy in addition to SEM and cathodoluminescence colours; stylolite material was also defined based on this principle. No staining in either core or thin section samples (e.g., by Alizarin Red-S) was used to distinguish between calcite and dolomite.

\section{Results}

\subsection{Well Core Lithology}

The studied wells feature an original depositional facies composed of regularly-spaced mm-bedded carbonate mudstones, which is concordant with existing literature on the $\mathrm{Ca} 2$ (e.g., Strohmenger et al., 1996). However, they appear diagenetically altered to show varying degrees of calcitised dolomite interlayered with dolomite. Dolomite and various degrees of calcitised dolomite have been distinguished based on the visual analysis of core photographs, where calcitised dolomite has varying shades of moderate / dark grey whereas dolomite is light brown. Dolomitised units are often found in narrow $\mathrm{cm}$-scale vertical intervals associated with higher abundance of bedding-parallel stylolites, or as horizontal laminations with gradational contacts against the surrounding calcitised dolomite. Veins occur in all core lithologies and can be classified as either vuggy, intermediate or fracture type. Vein cements are formed by calcite, anhydrite or dolomite with minor amounts of fluorite and metal sulphides found predominantly associated with anhydrite veins. Cements are distinguished based on thin section analysis. Dissolution vugs and open fractures are typically not proximal to areas with abundant vein cementation (Fig. 2e) and contribute to reservoir porosity. Vugs tend to be partially infilled with either calcite or anhydrite. Open fractures are less abundant in proximity to stylolites.

\subsection{Stylolite and Vein Abundance}

Stylolites occur in all cores with densities ranging from 5 to $50 / \mathrm{m}$ (number per metre) and are compared with schematic lithology logs in Fig. 6. Most stylolites are classified as sedimentary (also called diagenetic), because they are orientated at $<30^{\circ}$ to bedding, contrary to tectonic stylolites that make higher angles with bedding and can cross-cut sedimentary stylolites. Teeth are sub-vertically orientated indicating that the principal compressive stress direction is vertical. Stylolite density in well A is 6-30/m, with an increasing density at the depth range 3,970 - 3,988 $\mathrm{m}$. Density values increase progressively until a sharp decrease between 3,990 - 4,010 $\mathrm{m}$ followed by a rapid increase and gradual decline in a step-like pattern before sharply declining again at $4,054 \mathrm{~m}$, correlating with increasing calcitised dolomite intervals. Stylolite density in well B progressively decreases with depth in the shallow dolomitic units, becoming higher in the calcitised dolomite intervals between 3,955$4,040 \mathrm{~m}$. Density in this well ranges between $20-30 \mathrm{n} / \mathrm{m}$. Stylolite density in well C ranges from 5 to $27 / \mathrm{m}$, with the highest density interval between 4,000 and 4,010 m. Density fluctuates progressively with depth, correlating with frequent changes in lithology, and is lowest when in proximity to calcitic intervals. Stylolite density in well D ranges between 5 and $37 / \mathrm{m}$ throughout the well, with the highest density at $3,750 \mathrm{~m}$. Density increases with depth in the partially calcitised dolomite intervals whilst appearing unaffected by the increase in calcitic intervals between 3,770 and $3,790 \mathrm{~m}$. Stylolites have a density range between 14 
and $30 / \mathrm{m}$ in well E. Sampling intervals are larger in well E due to large quantities of unlabelled core boxes creating inaccuracies with core depth interpolation, and thus resulting in unreliable depth trend estimations. Stylolite density increases with depth and features sudden increases in density at $3,930 \mathrm{~m}$ and $3,950 \mathrm{~m}$. The trend is independent from lithological variations and is likely due to core box sampling errors.

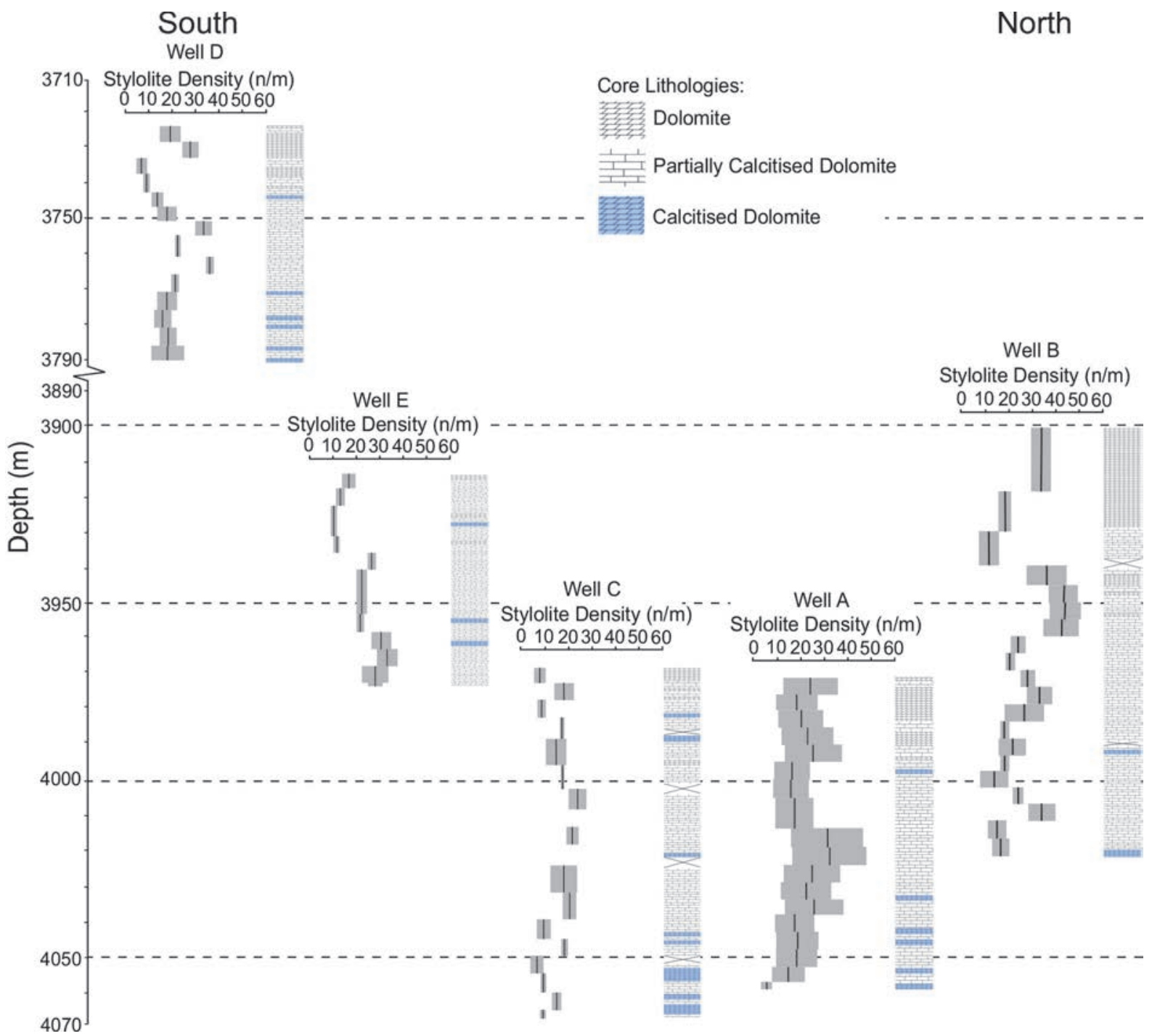

Figure 6. Structural $\log$ of stylolite measurements collected from wells A-E. Logs are depth matched to measurements and spatially arranged from south to north. Grey areas show error to two standard deviations. 


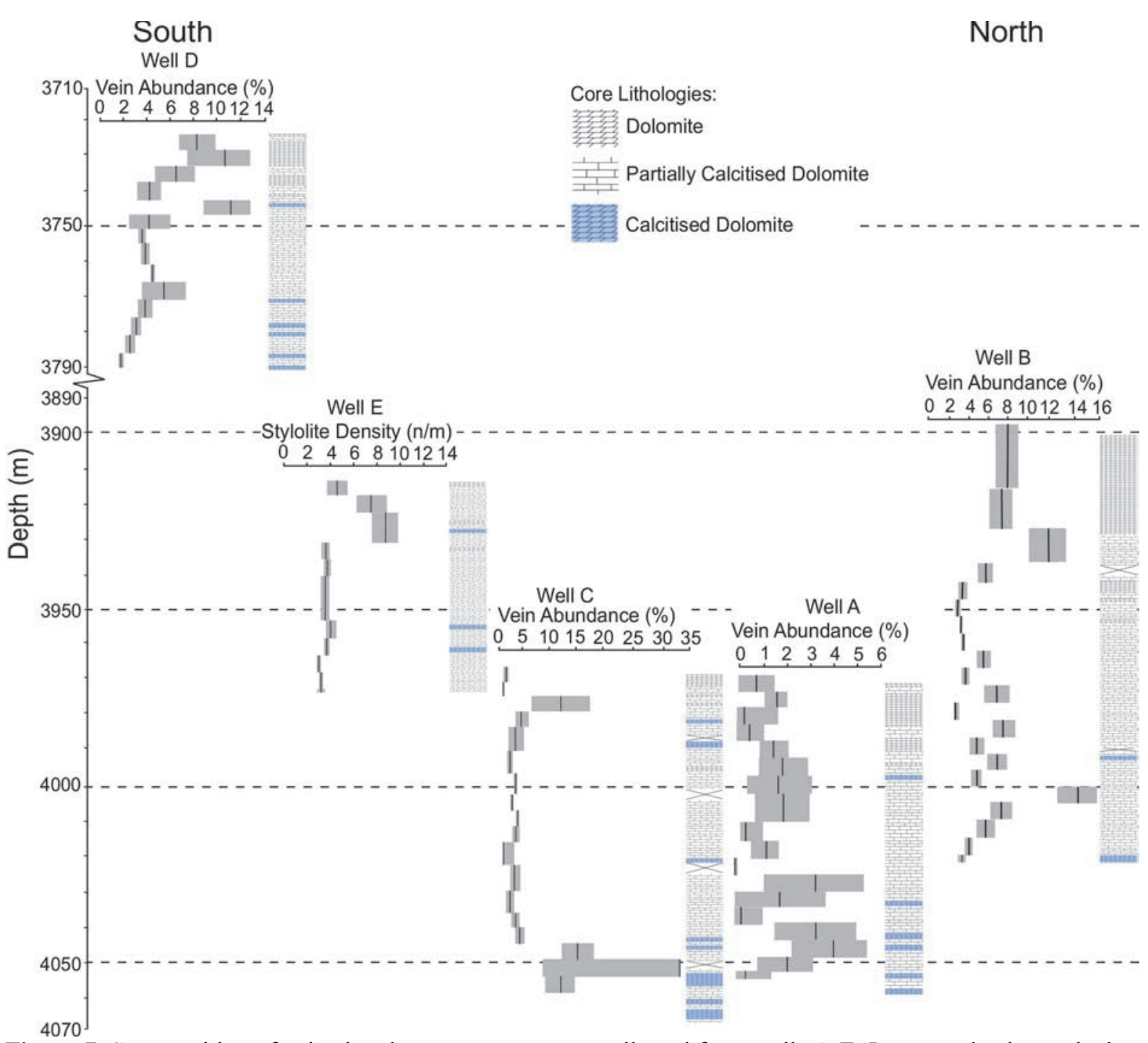

Figure 7. Structural log of vein abundance measurements collected from wells A-E. Logs are depth matched to measurements and spatially arranged from south to north. Grey areas show error to two standard deviations.

The abundance of veins (vuggy, intermediate and fracture) observed in core ranges between 1-35\% and are compared with schematic logs in Fig. 7. Vein abundance in well A ranges from $1-5 \%$, showing an increasing trend between 3,970-4,005 $\mathrm{m}$ followed by a minor decrease at 4,012-4,024 $\mathrm{m}$ where the average abundance is $1.5 \%$. Between $4,026-4,054 \mathrm{~m}$ measurements follow a 'sawtooth' style pattern of fluctuating abundances. Vein abundance in well $\mathrm{B}$ has a low error range however increased interpolation at 3,896-3,926 $\mathrm{m}$ creates uncertainty. Abundance declines at 3,950 $\mathrm{m}$ followed by an increase until 4,006 $\mathrm{m}$. Vein abundance in well $\mathrm{C}$ is between $1-5 \%$ with a maximum of $35 \%$ at $4,054 \mathrm{~m}$. Vein abundance in well D progressively declines between $3,724-3,786 \mathrm{~m}$, but has an abundance of $11 \%$ at $3745 \mathrm{~m}$. A gradual decline in abundance from 3,724-3,744 $\mathrm{m}$ is followed by a slight increase until $3,760 \mathrm{~m}$, later followed by a steep decline to $3,786 \mathrm{~m}$. Vein abundance in well $\mathrm{E}$ has a strongly polarized distribution with abundances between 3,910-3,920 m ranging from 4-12\% whereas the rest of the section has a narrow range between $0-2 \%$.

Data from cross-cutting events (Table 2) show that bedding-parallel stylolites predominantly cut vuggy, intermediate, and fracture veins throughout all sampled wells. Vuggy, intermediate and fracture veins, however, are still observed cross-cutting beddingparallel stylolites. From observed bedding-parallel stylolite and vein relationships, $18 \%$ of 
measurements are from veins cross-cutting stylolites representing 115 interactions. Fracture veins interact with bedding-parallel stylolites in a way that $62.4 \%$ of interactions show stylolites intersecting fracture veins (Fig. 2), accounting for 116 interactions. Inter-vein relationships are low within well data. Vuggy and intermediate veins predominantly cut fracture veins with twenty recorded cross-cutting interactions. There is a total of forty interactions where tectonic stylolites cross-cut bedding-parallel stylolites (Fig. 2e) with only localised occurrences of tectonic stylolites being cut. The frequency of cross-cutting interactions between tectonic stylolites and veins is low, with only twenty-six recorded interactions, where tectonic stylolites predominantly cut veins.

Table 2. Cross-cutting relationships between different structures and diagenetic products in wells A-E.

\begin{tabular}{|c|c|c|c|c|c|c|c|c|}
\hline \multirow[t]{3}{*}{ Well A } & & & & & & & & \\
\hline & \multicolumn{2}{|c|}{$\begin{array}{l}\text { Bedding parallel } \\
\text { stylolite }\end{array}$} & \multicolumn{2}{|c|}{ Tectonic stylolite } & \multicolumn{2}{|c|}{$\begin{array}{c}\text { Vuggy + } \\
\text { Intermediate } \\
\text { Veins }\end{array}$} & \multicolumn{2}{|c|}{ Fracture Veins } \\
\hline & Cut & Cut by & Cut & Cut by & Cut & Cut by & Cut & Cut by \\
\hline $\begin{array}{l}\text { Bedding parallel } \\
\text { Stylolite }\end{array}$ & & & 7 & 0 & 6 & 45 & 4 & 7 \\
\hline Tectonic Stylolite & 0 & 7 & & & 1 & 2 & 0 & 1 \\
\hline $\begin{array}{l}\text { Vuggy + } \\
\text { Intermediate } \\
\text { Veins }\end{array}$ & 45 & 6 & 2 & 1 & & & 1 & 0 \\
\hline Fracture Veins & 7 & 4 & 1 & 0 & 0 & 1 & & \\
\hline
\end{tabular}

\begin{tabular}{|l|c|c|c|c|c|c|c|c|}
\cline { 2 - 10 } & \multicolumn{10}{|c|}{$\begin{array}{c}\text { Bedding parallel } \\
\text { stylolite }\end{array}$} & \multicolumn{2}{c|}{ Tectonic stylolite } & \multicolumn{2}{c|}{$\begin{array}{c}\text { Vuggy + } \\
\text { Intermediate } \\
\text { Veins }\end{array}$} & \multicolumn{2}{c|}{ Fracture Veins } \\
\cline { 2 - 10 } & Cut & Cut by & Cut & Cut by & Cut & Cut by & Cut & Cut by \\
\hline $\begin{array}{l}\text { Bedding parallel } \\
\text { Stylolite }\end{array}$ & 8 & & 21 & 8 & 0 & 76 & 45 & 61 \\
\hline $\begin{array}{l}\text { Tectonic Stylolite } \\
\text { Vuggy + } \\
\text { Intermediate } \\
\text { Veins }\end{array}$ & 76 & 0 & 12 & 1 & & & 1 & 3 \\
\hline Fracture Veins & 61 & 45 & 3 & 0 & 3 & 1 & & \\
\hline
\end{tabular}

\begin{tabular}{l|c|c|c|c|c|c|c|c|}
\cline { 2 - 10 } Well C & \multicolumn{10}{|c|}{$\begin{array}{c}\text { Bedding parallel } \\
\text { stylolite }\end{array}$} & \multicolumn{2}{c|}{ Tectonic stylolite } & \multicolumn{2}{c|}{$\begin{array}{c}\text { Vuggy + } \\
\text { Intermediate } \\
\text { Veins }\end{array}$} & \multicolumn{2}{c|}{ Fracture Veins } \\
\cline { 2 - 10 } \multicolumn{1}{c|}{} & Cut & Cut by & Cut & Cut by & Cut & Cut by & Cut & Cut by \\
\hline $\begin{array}{l}\text { Bedding parallel } \\
\text { Stylolite }\end{array}$ & 0 & 5 & 5 & 0 & 0 & 49 & 6 & 15 \\
\hline Tectonic Stylolite & 0 & & & 0 & 3 & 1 & 0 \\
\hline $\begin{array}{l}\text { Vuggy + } \\
\text { Intermediate } \\
\text { Veins }\end{array}$ & 49 & 0 & 3 & 0 & & & 0 & 4 \\
\hline Fracture Veins & 15 & 6 & 0 & 1 & 4 & 0 & & \\
\hline
\end{tabular}

\begin{tabular}{|c|c|c|c|c|c|c|c|c|}
\hline \multirow{3}{*}{ Well D } & \multirow{2}{*}{\multicolumn{2}{|c|}{$\begin{array}{l}\text { Bedding parallel } \\
\text { stylolite }\end{array}$}} & \multirow{2}{*}{\multicolumn{2}{|c|}{ Tectonic stylolite }} & \multirow{2}{*}{\multicolumn{2}{|c|}{$\begin{array}{c}\text { Vuggy + } \\
\text { Intermediate } \\
\text { Veins }\end{array}$}} & \multirow{2}{*}{\multicolumn{2}{|c|}{ Fracture Veins }} \\
\hline & & & & & & & & \\
\hline & Cut & Cut by & Cut & Cut by & Cut & Cut by & Cut & Cut by \\
\hline $\begin{array}{l}\text { Bedding parallel } \\
\text { Stylolite }\end{array}$ & & & 4 & 0 & 15 & 39 & 6 & 21 \\
\hline Tectonic Stylolite & 0 & 4 & & & 0 & 0 & 2 & 0 \\
\hline $\begin{array}{l}\text { Vuggy + } \\
\text { Intermediate } \\
\text { Veins }\end{array}$ & 39 & 15 & 0 & 0 & & & 2 & 1 \\
\hline Fracture Veins & 21 & 6 & 0 & 2 & 1 & 2 & & \\
\hline
\end{tabular}




\begin{tabular}{|c|c|c|c|c|c|c|c|c|}
\hline & \multicolumn{2}{|c|}{$\begin{array}{l}\text { Bedding parallel } \\
\text { stylolite }\end{array}$} & \multicolumn{2}{|c|}{ Tectonic stylolite } & \multicolumn{2}{|c|}{$\begin{array}{c}\text { Vuggy + } \\
\text { Intermediate } \\
\text { Veins }\end{array}$} & \multicolumn{2}{|c|}{ Fracture Veins } \\
\hline & Cut & Cut by & Cut & Cut by & Cut & Cut by & Cut & Cut by \\
\hline $\begin{array}{l}\text { Bedding parallel } \\
\text { Stylolite }\end{array}$ & & & 3 & 0 & 20 & 104 & 8 & 8 \\
\hline Tectonic Stylolite & 0 & 3 & & & 0 & 0 & 0 & 0 \\
\hline $\begin{array}{l}\text { Vuggy + } \\
\text { Intermediate } \\
\text { Veins }\end{array}$ & 104 & 20 & 0 & 0 & & & 8 & 12 \\
\hline Fracture Veins & 8 & 8 & 0 & 0 & 12 & 8 & & \\
\hline
\end{tabular}

\subsection{Statistical Analysis of Stylolite Networks}

Stylolite spacing and teeth amplitude measurements from each well do not show significant morphological correlations (Fig. 8). Stylolite spacing measurements fit a lognormal distribution, with a p-value less than 0.05 (Fig. 9). The distribution of data is biased towards smaller spacing measurements, in a way that larger spacing measurements vary since gaps in core limit the measurable extent between stylolites, whilst $<10$ pixel stylolites have not been measured. Removing undersampled spacing measurements, spacings less than 28 $\mathrm{mm}$, ensures a minimum bin size of ten samples and subsequently causes the data to fit an exponential distribution. A control sample of 40 measurements was compared to initial spacing measurements to evaluate the margin of error, showing that stylolite spacing had an error of $20.1 \%$ caused by resolution limitations. Teeth amplitude measurements also fit a lognormal distribution, with the removal of undersampled values, with amplitudes less than 10 $\mathrm{mm}$, fitting an exponential distribution. Teeth amplitude measurements had an error range of $44.6 \%$, caused by resolution and scaling issues with core photographs.

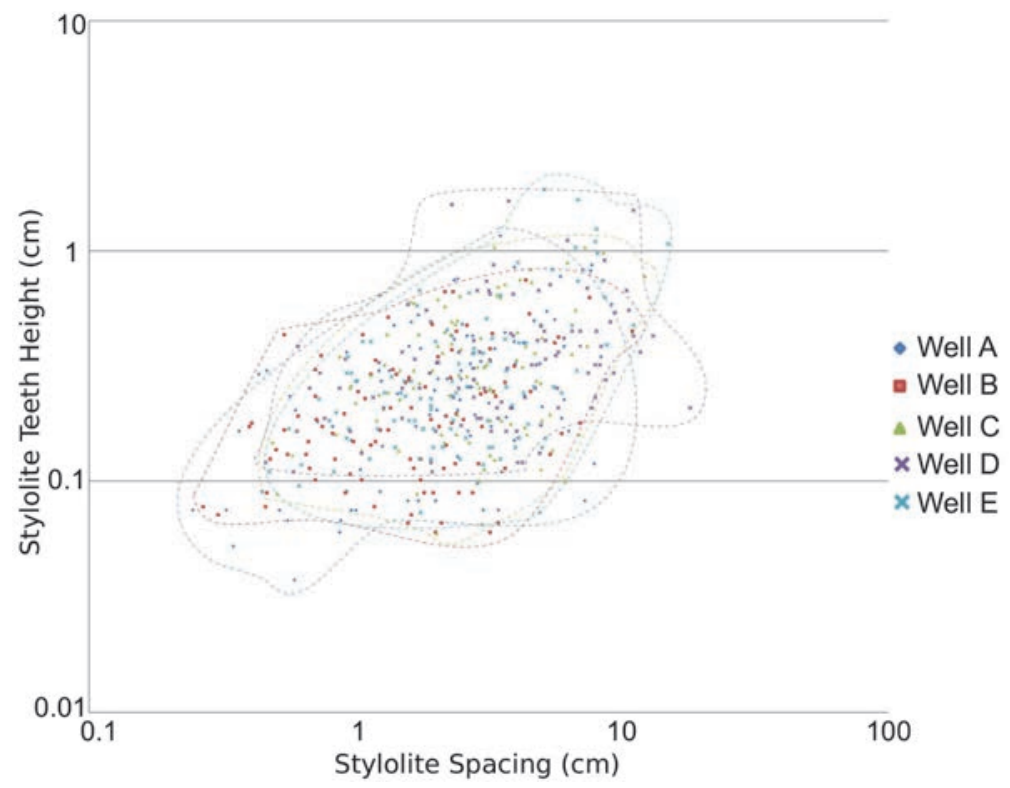

Figure 8. Scatter graph comparing measurements of stylolite spacing and teeth amplitude from wells A-E. 

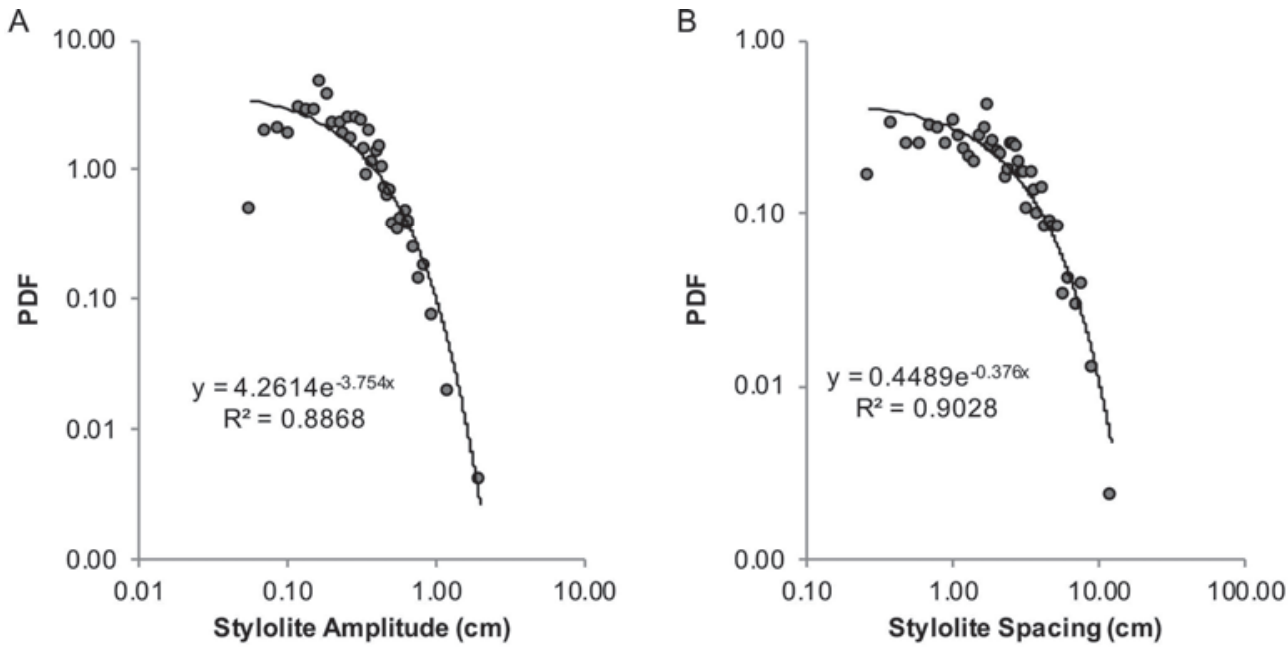

Figure 9. A. Log-normal distribution fit shown in log-log space for stylolite spacing measurements. B. Lognormal distribution fit shown in log-log space for stylolite teeth amplitude measurements. PDF represents the probability density function.

Sealing capacity measurements quantified the effectiveness of particular stylolites as baffles for fluid flow, following the classification of Koehn et al. (2016a) (Fig. 10). Stylolites are divided based on morphology where rectangular layer type stylolites have flat stylolite teeth, seismogram pinning type stylolites have irregular high amplitude teeth distributions, suture and sharp-peak type stylolites have angular teeth with varying amplitudes and wavelengths, and wave-like type stylolites have no defined teeth and have a weakly undulose geometry. Twenty measurements were collected per stylolite type in order to ascertain an average sealing capacity percentage. Suture and sharp-peak type stylolites have an average sealing capacity of $63 \%$, with less insoluble material on teeth flanks whilst concentrations are high on the caps of teeth and in low amplitude sutures (Fig. 10). Rectangular layer type stylolites support this trend but present an increased sealing capacity of $68 \%$. Seismogram pinning type stylolites share similar sealing capacities, with suture and sharp-peak type stylolites having an average sealing capacity of $67 \%$. Wave-like class stylolites provide the highest sealing capacity with an average of $89 \%$.

\subsection{Petrography}

\subsubsection{Dolomite Matrix 1 (DM1)}

Dolomite Matrix 1 occurs as planar-s to planar-e crystals with a polymodal size distribution (Fig. 11a). DM1 crystals are typically $20-50 \mu \mathrm{m}$ although they can reach up to $400 \mu \mathrm{m}$ next to porosity, and show concentric zoning from non-ferroan to ferroan under SEM using spectral analysis (Fig. 11a, b). DM1 varies in colour between pale grey to pale brown in plane-polarised light, whilst showing very dull red to no luminescence (Fig 9c). DM1 partially replaces the calcitic matrix of the depositional bioturbated algal laminated carbonate mudstone facies. The DM1 crystal mosaic is relatively porous, dominated by intercrystalline and micro-vuggy pore types, compared to the tighter surrounding calcitised dolomite (Fig. 11b). DM1 crystal cores are often corroded to create small cavities that are partially filled with calcite, indicating a calcitisation stage after DM1 formation. 


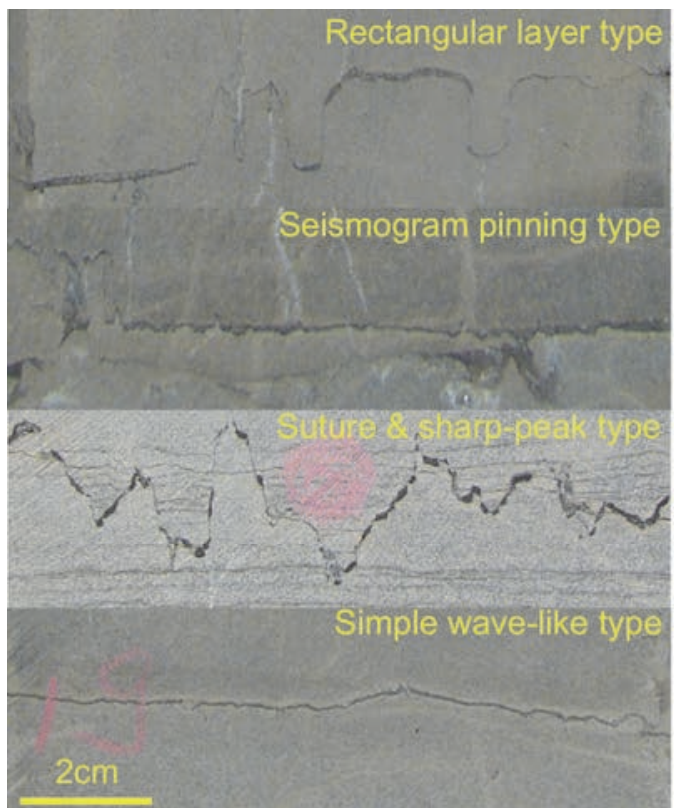

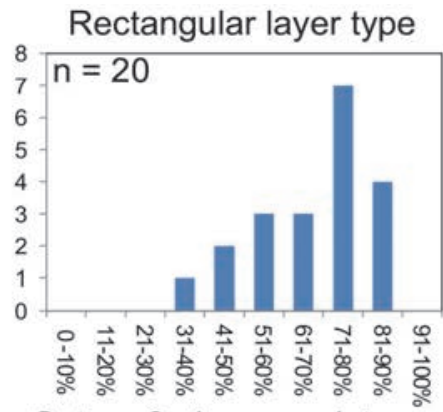

Suture \& sharp-peak type

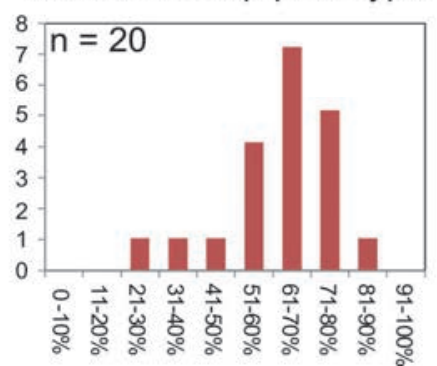

Seismogram pinning type

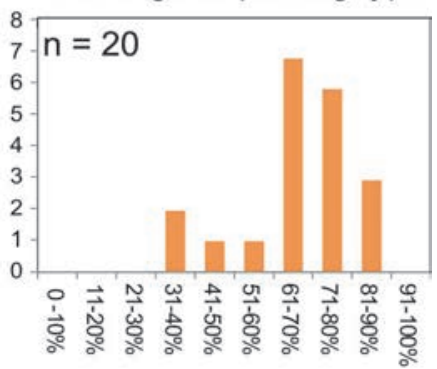

Simple wave-like type

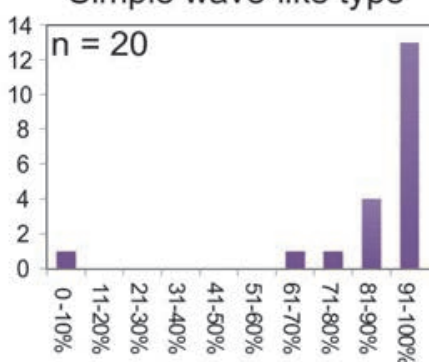

Figure 10. Core photographs of stylolite types classified by Koehn et al. (2016) alongside histograms measuring stylolite sealing capacity $(\%)$.

\subsubsection{Calcite Matrix 1 (CM1) (Calcitisation sensu Schoenherr et al., 2018)}

Calcite matrix 1 is extensive throughout the core samples, featuring fine-crystalline sub- to anhedral crystals that form a tight and low-porosity mosaic. CM1 replaces DM1 crystals and fills intercrystalline and micro-vuggy porosity in dolomitised areas. The extent of calcitisation varies within the wells and between them. Higher porosity is preserved due to the incomplete fill of intercrystalline pores by calcite (Fig 9b). CM1 crystals vary in colour between grey and dull yellow in plane-polarised light, and have a dull to moderate red luminescence (Fig 9c).

\subsubsection{Calcite Cement 1 (CC1)}

Calcite cement 1 is made of small blocky subhedral crystals ranging between $60-170 \mu \mathrm{m}$ that form blocky crystal mosaics (Fig. 11d). CC1 crystals show weak green-pink pleochroism in plane-polarised light and third order birefringence colours in cross-polarised light. CC1 crystals have a homogenous dull red luminescence (Fig. 11c). CC1 fills fractures that cut stylolites, and thus postdates stylolitisation (Fig. 11e), but are post-dated by later-stage calcite cements (Fig. 11e).

\subsubsection{Calcite Cement Group (CC2-5)}

Calcite cement 2 (CC2) forms $0.25-0.5 \mathrm{~mm}$ blocky sub- to anhedral crystals and predominantly fills vugs and large brecciated veins (Fig. 11f). Crystals have moderate redorange luminescence, with weakly defined dull red zoning seen near the centre of larger crystals in veins (Fig. 12a). Minor bright red and orange zoning is found in brecciated veins. This is, however, not extensive and most crystals show homogenous luminescence. CC2 veins cross-cut $\mathrm{CC} 1$ (Fig. 12b) and represent the earliest cement in the group, post-dated by later-stage calcite and anhydrite phases. Calcite cement 3 (CC3) consists of fine subhedral crystals between $10-50 \mu \mathrm{m}$ and is situated exclusively on vein walls to form a thin rim (Fig. $12 \mathrm{c}, 9 \mathrm{e})$ that is later post-dated by calcite cement 4 (CC4). CC3 crystals show third-order birefringence in cross-polarised light and have a dull red luminescence (Fig. 12d). CC4 has a 
polymodal crystal size distribution between $0.3 \mathrm{~mm}$ and $0.6 \mathrm{~mm}$. Crystals are predominantly blocky and subhedral, although minor occurrences of anhedral dogtooth crystals are present (Fig. 12c). Crystals have a dull-moderate luminescence which is brighter than the earlier CC3 crystals, with dogtooth crystals showing a weakly defined sector zoned luminescence pattern (Fig. 12d). Both CC3 and CC4 are post-dated by stylolitisation, which caused asymmetric and partial removal of $\mathrm{CC} 3$ cement from veins. $\mathrm{CC} 4$ can be seen as a minor phase in vugs, post-dated by anhydrite. Calcite cement 5 (CC5) consists of sub- to anhedral blocky crystals approximately $400 \mu \mathrm{m}$ in size (Fig. 12e, f) that occupy fracture and vuggy porosity in veins. Crystals have a high relief and well-defined twinning in plane-polarised light, with dull luminescence (Fig. 13a) that occasionally shows orange zoning when viewed using cold CL. Large crystals also develop in vugs. CC5 pre-dates anhydrite and post-dates CC3 and CC4.

\subsubsection{Ferroan Dolomite (FD)}

Ferroan dolomite (FD) forms $25-50 \mu \mathrm{m}$ crystals with a planar-s texture and exclusively fills fractures. Crystals have a moderate-pale grey colour in BSEM (Fig. 13b). Some FD rhombs were partially replaced by a later stage calcite that also occupies intercrystalline pores. FD is cut, and thus post-dated, by metal sulphides and stylolites (Fig. 13c).

\subsubsection{Metal Sulphides (MS)}

Metal sulphides, pyrite and sphalerite, are distributed throughout core sections, where they mostly fill porosity associated with well-developed stylolites and vugs within CM1 (Fig. 13d). Pyrite filling stylolitic porosity is framboidal with an average diameter between 25-50 $\mu \mathrm{m}$ (Fig. 13e). Sphalerite has much larger crystals $(50-600 \mu \mathrm{m})$ than pyrite (Fig. 13d), and is found in association with pyrite, stylolites and anhydrite. Pyrite replaces CC5 in veins and thus precipitated after calcite cementation. Based on the distribution of idiomorphic pyrite crystals within cemented veins, pyrite formed prior to initial anhydritisation.

\subsubsection{Anhydrite Cement 1 (AC1)}

Anhydrite cement 1 (AC1) forms blocky and tabular euhedral crystals, with lengths up to $400 \mu \mathrm{m}$ and approximate widths between 50-100 $\mu \mathrm{m}$, that fill vugs and replace CM1 (Fig. 13f, 12a). AC1 crystals typically fill the centre of vugs after earlier calcitisation, and thus postdate calcite cementation (Fig 12a). AC1 crystals that appear more tabular are found exclusively in vugs without earlier calcite phases. AC1 crystals have a high relief in planepolarised light and show second-order birefringence. Tabular crystals show evidence of growth competition (Fig. 14b). AC1 post-dates CC3 and CC4, metal sulphides, and predates fluorite precipitation.

\subsubsection{Anhydrite Cement 2 (AC2)}

Anhydrite cement 2 (AC2) forms fine crystalline fibrous crystals, up to $0.5 \mathrm{~mm}$ long, that show second-order birefringence (Fig. 14a). AC2 fills vugs with fibrous crystals dominantly orientated parallel to the pore wall, whilst the centres of vugs have occasional fibrous crystals along with fine-grained blocky to subhedral anhydrite. AC2 post-dates most calcite phases, can be bound by stylolites, and is not found in association with metal sulphides. 

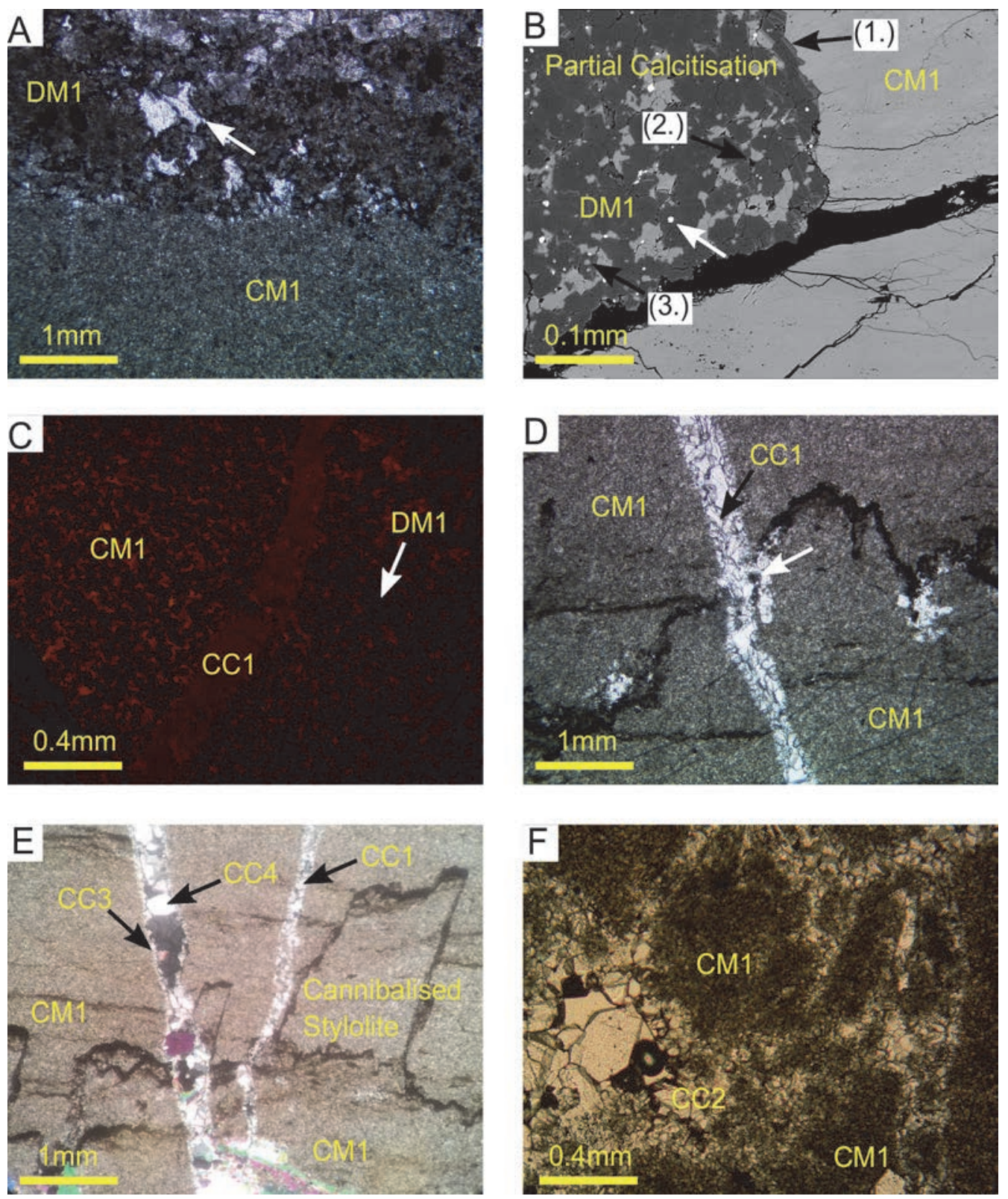

Figure 11. A. PPL thin section of DM1 and CM1. White arrow shows sparry calcite B. SEM photograph of DM1 (dark grey) in a tight CM1 matrix (light grey). Metal sufides are present within DM1 (white arrow) alongside non-ferroan to ferroan dolomite zonation (arrow No. 1), intercrystalline porosity (arrow No. 2), and calcitisation corroding dolomite cores (arrow No. 3). Fractures are the largest contributor to porosity in CM1 C. $\mathrm{CL}$ image of $\mathrm{CC} 1$ fracture fill with homogenous dull red luminescence in $\mathrm{CM} 1$, with darker areas representing DM1. D. PPL thin section of CC1 postdating a stylolite, with stylolite traces preserved in CM1 breccia within the vein (white arrow). E. PPL photograph of multiple calcite veins in CM1 which cross-cut a cannibalised stylolite. F. PPL image of CC2 fracture fill alongside CM1 breccia. 

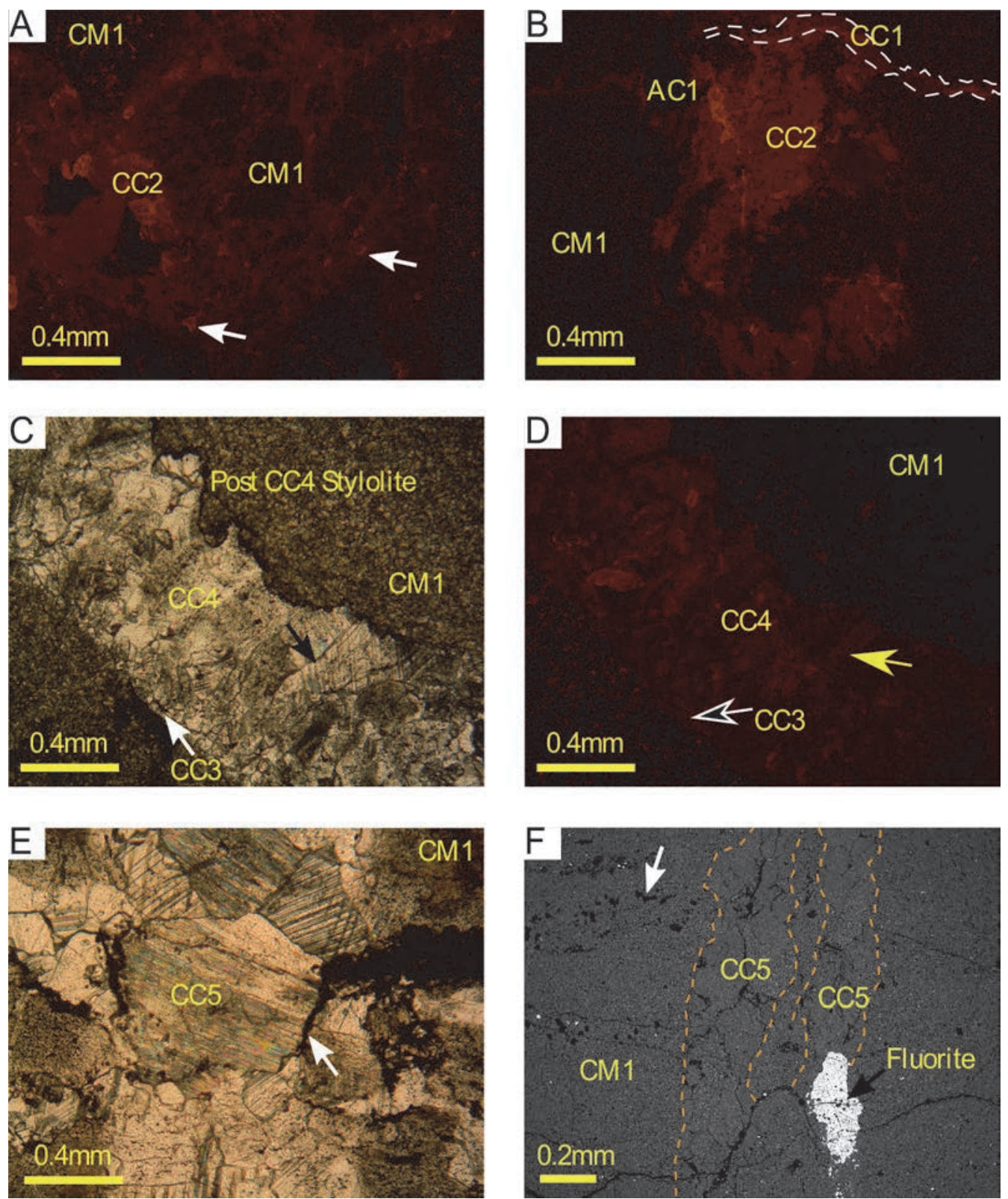

Figure 12. A. CL image of CC2 fracture fill with dull/moderate red luminescence in blocky subhedral crystals. Minor dull to moderate red zoning in crystals (white arrows), alongside minor amounts of fracture porosity. B. $\mathrm{CL}$ image of vuggy $\mathrm{CC} 2$ postdating $\mathrm{CC} 1$ in a partially calcitised dolomite matrix. AC1 appears as black tabular crystals and postdates all calcite phases. The approximate location of the $\mathrm{CC} 1$ vein wall has been highlighted relative to CC2 (white dashed line). C. PPL thin section of CC3 (white arrow) and CC4 as fracture fill adjacent to a stylolite. CC4 contains anhedral dogtooth crystals (black arrow) which have been partially removed by postdated stylolitisation. D. CL image of CC3 and CC4. Dogtooth CC4 crystal shows sectoral zoning (yellow arrow) whilst CC3 crystals cement the edge of the vein (black arrow with white outline). E. PPL thin section of CC5 displaying well defined twinning alongside discontinuous stylolite seams (white arrow). F. SEM photograph of CC5 in a calcitised matrix which terminates against a stylolite; vein walls are traced (dashed orange). Intercrystalline porosity is preserved in CM1. 

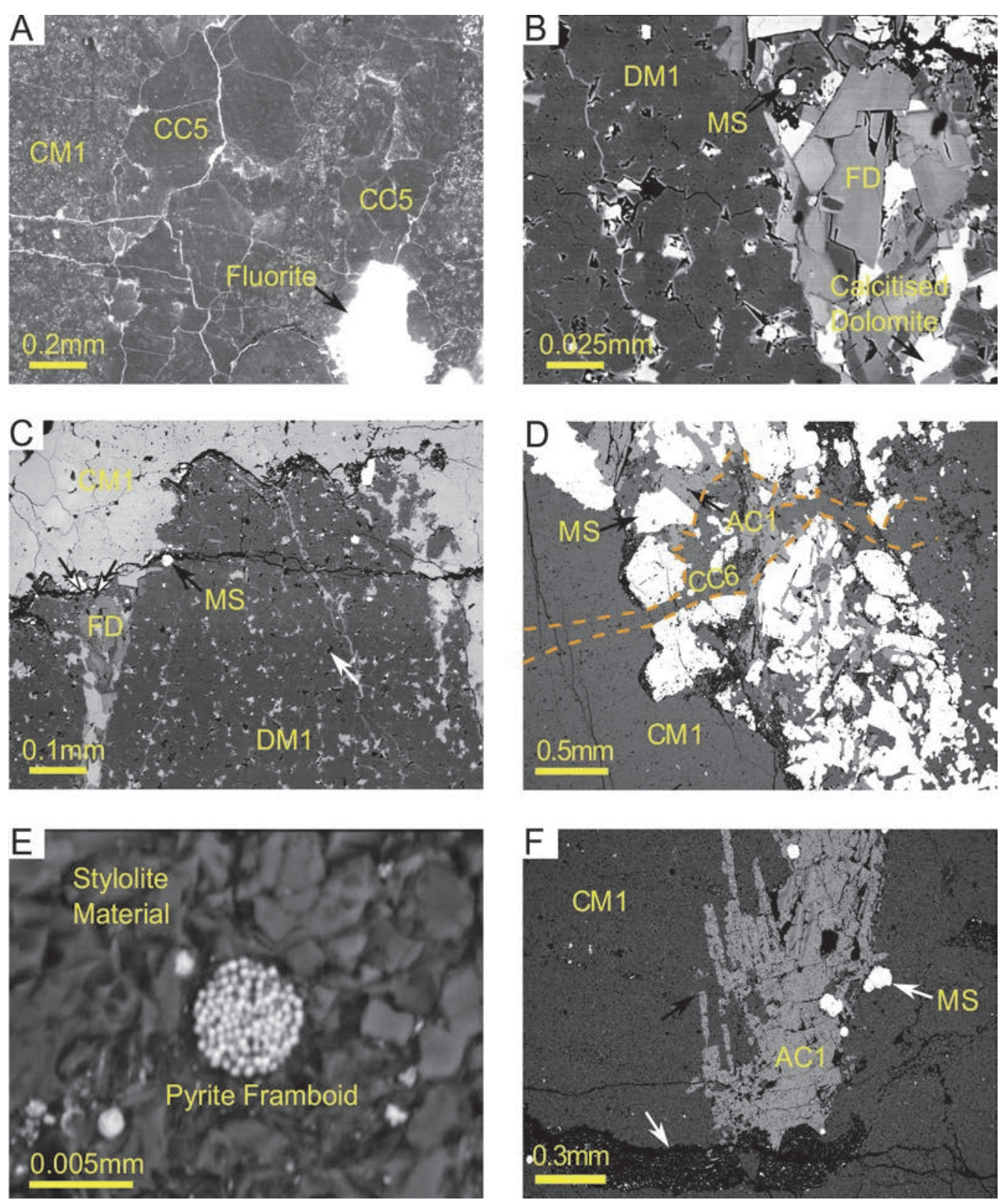

Figure 13. A. SEM CL image of CC5 fracture fill with later replacement fluorite (black arrow). B. SEM photograph of FD fracture fill in a calcitised matrix. FD is bound by a stylolite (white arrow) and found alongside pyrite (black arrow). C. SEM photograph of a dolomite-calcitised dolomite front bound by a stylolite. Stylolites contain metal sulphides whilst FD occurs as fracture fill within DM1. Stylolite partially cross-cuts FD crystals (white arrows with black outline). Intercrystalline porosity is preserved in DM1 (white arrow). D. SEM photograph of metal sulphides and anhydrite bound by stylolites in a calcitised matrix. CC6 postdates MS and $\mathrm{AC} 1$ (an approximate vein trace is shown by the dashed line). E. SEM photograph of framboidal pyrite within a stylolite. F. SEM photograph of AC1 bound by a stylolite containing metal sulphides (white arrow). Well defined tabular anhydrite replaces CM1 (black arrow). 

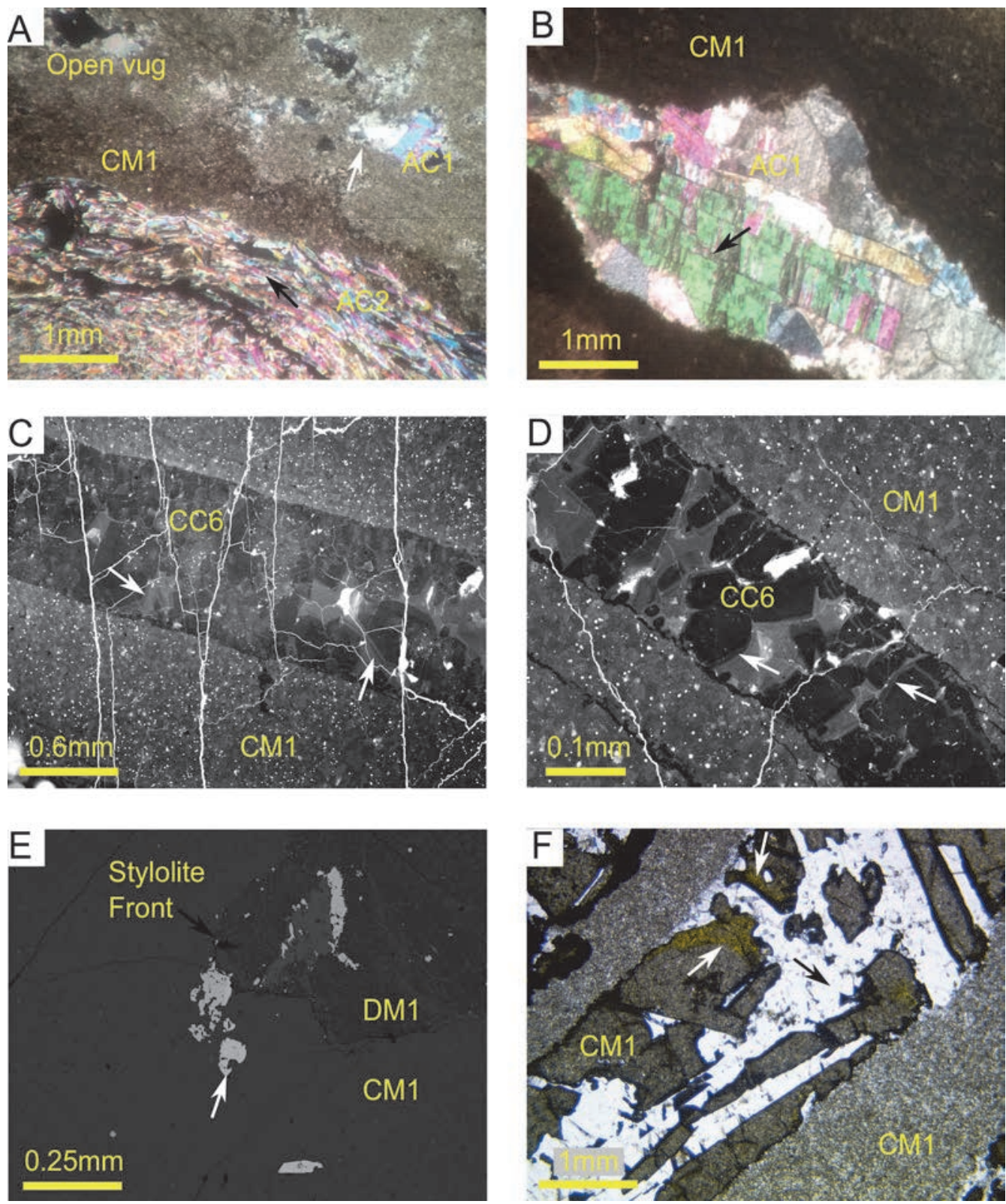

Figure 14. A. PPL thin section of AC1 postdating partial calcitisation of a vug (white arrow) and of fibrous AC2 which occupied larger vugs (black arrow). B. AC1 vug within CM1. Tabular AC1 crystals are slightly deformed suggesting minor growth competition (black arrow). C. SEM CL image of CC5 fracture fill with blocky crystals showing weak concentric zoning (white arrows). D. SEM CL image of CC5 fracture fill with prominent zoning (white arrows). E. Dolomite-calcitised dolomite front bound by a stylolite (dashed white line). Celestine and fluorite crystals act as a late-stage replacement phase (white arrow), identified by BSEM-EDAX. F. PPL photograph of CM1 breccia within calcite fracture fill. CM1 breccia partially replaced by siderite (white arrows).

\subsubsection{Calcite Cement 6 (CC6)}

Calcite Cement 6 (CC6) form subhedral blocky crystals ranging in size between 50-300 $\mu \mathrm{m}$ (Fig. 14c). CC6 crystals fill fractures that both pre- and post-date stylolites. CC6 crystals are smaller in proximity of the walls (Fig. 14d) than in the centre of the veins, both showing similar BSEM-CL luminescence with a characteristic pale concentric luminescence zoning. BSEM-EDAX analyses show that CC6 is slightly ferroan (Fig. 14c). 


\subsubsection{Fluorite}

Fluorite is found in low abundance exclusively within veins and forms fine, euhedral crystals (Fig. 14e). Crystal sizes in the matrix are $\sim 50-150 \mu \mathrm{m}$ whilst vein replacement crystals can be up to $300 \mu \mathrm{m}$. Fluorite fills vugs in CM1, and replaces calcite and anhydrite cements filling veins.

\subsubsection{Celestine}

Celestine is a late-stage mineral that precipitated in micro-vuggy pores with sizes between $50-150 \mu \mathrm{m}$, and is found in low abundance relative to fluorite (Fig. 14e). Celestine predominantly occurs in CM1 and partially overlaps stylolite fronts indicating that precipitation postdated stylolitisation.

\subsubsection{Siderite}

Siderite is a minor diagenetic product compared to the aforementioned phases. Very fine crystals are manifested as yellow staining in the tight calcitised matrix under plane-polarised light, commonly in the proximity of calcite veins (Fig. 14f). Siderite is typically more abundant in the collapsed and brecciated vein walls of calcite and anhydrite than in the calcitised matrix, postdating calcitisation and anhydritisation phases.

\section{Discussion}

In this section, we discuss the paragenetic evolution of the $\mathrm{Ca} 2$ mudstones in the northern Zechstein fairway in relation to the burial history and structural development, and what the impact of stylolites is on diagenesis and subsequent reservoir quality.

\subsection{Paragenetic sequence of the Ca2 unit in the Pompeckj Block}

The geodynamic evolution of the PB had direct implications on the timing of diagenetic events that took place in the $\mathrm{Ca} 2$, subsequently altering the temporal and spatial distribution of reservoir quality. Diagenetic events are subdivided depending on their timing with respect to the burial stages (burial, quiescence and uplift) defined by Baldschuhn et al. (1991), Betz et al. (1987) and Schwarzer and Littke (2007) for the LSB and PB (Fig. 15). The boundary between shallow and intermediate burial is based on the scheme by Choquette and Pray (1970). The most important diagenetic events in the $\mathrm{Ca} 2$ are dolomitisation, calcitisation, stylolitisation and successive periods of vein cementation by calcite and anhydrite, which will be discussed in the following paragraphs.

Cross-cutting relationships indicate that bedding-parallel stylolites both cut and are cut by vuggy and intermediate veins implying that both structures formed during basin subsidence. Bedding-parallel stylolitisation and vein cementation were not likely single events and instead probably occurred in pulses during progressive subsidence. Tectonic stylolites have minimal interaction with veins suggesting that vein emplacement predominantly predates tectonic stylolites and therefore inversion-related microstructures in the PB. The limited number of interactions between tectonic stylolites and veins may, however, be due to geometry as tectonic stylolites are likely to be sub-parallel to both veins and the well, resulting in a lower number of potential cross-cutting relationships with each other. Fractures cemented by CC6 were the only veins shown to cross-cut, and therefore postdate, tectonic 
stylolitisation. The lack of interaction between different vein morphologies makes it difficult to establish relative age relationships. Cross-cutting measurements would suggest that all vein morphologies formed syngenetically. However, vuggy/intermediate veins are likely to postdate fracture veins, which likely formed during early periods of rapid subsidence. Tectonic stylolites predominantly cut bedding-parallel stylolites, but they can also be cut by bedding-parallel stylolites. This would suggest that tectonic stylolitisation was postdated by a later phase of bedding-parallel stylolitisation.

\begin{tabular}{|c|c|c|c|c|}
\hline Diagenetic Event & \multicolumn{4}{|c|}{ Diagenetic Environment } \\
\hline Phase / Process & Shallow Burial & Intermediate Burial & Inversion & Intermediate Burial \\
\hline & \multicolumn{2}{|c|}{$55^{\circ} \mathrm{C}$} & \multicolumn{2}{|c|}{$135^{\circ} \mathrm{C}$} \\
\hline \multicolumn{5}{|l|}{ Dolomite Matrix 1} \\
\hline \multicolumn{5}{|l|}{$\begin{array}{c}\text { Dolomite } \\
\text { Dissolution }\end{array}$} \\
\hline $\begin{array}{c}\text { Stylolitisation } \\
\text { (Beddding Parallel) }\end{array}$ & \multicolumn{2}{|c|}{--} & & \\
\hline \multicolumn{5}{|l|}{$\begin{array}{l}\text { Dedolomitisation } \\
\text { (Calcite Matrix 1) }\end{array}$} \\
\hline \multicolumn{5}{|l|}{ Fracturing } \\
\hline \multicolumn{5}{|l|}{ Calcite Cement 1} \\
\hline \multicolumn{5}{|l|}{ Calcite Cement 2-5 } \\
\hline $\begin{array}{l}\text { Stylolitisation } \\
\text { (Tectonic) }\end{array}$ & & & \multicolumn{2}{|l|}{$\leftarrow------\rightarrow$} \\
\hline \multicolumn{5}{|l|}{ Ferroan Dolomite } \\
\hline \multicolumn{5}{|l|}{ Pyrite } \\
\hline \multicolumn{5}{|l|}{ Siderite } \\
\hline \multicolumn{5}{|l|}{ Sphalerite } \\
\hline \multicolumn{5}{|l|}{ Anhydrite Cement 1} \\
\hline \multicolumn{5}{|l|}{ Anhydrite Cement 2} \\
\hline \multicolumn{5}{|l|}{ Calcite Cement 6} \\
\hline \multicolumn{5}{|l|}{ Fluorite } \\
\hline \multicolumn{5}{|l|}{ Celestine } \\
\hline & $\sim 2$ & $\overline{\mathrm{Ma}}$ & $0 \mathrm{Ma}$ & $\mathrm{Ma}$ \\
\hline & $\sim 1$ & $0 \mathrm{~m}$ & $00 \mathrm{~m}$ & $00 \mathrm{~m}$ \\
\hline
\end{tabular}

Figure 15. Paragenetic sequence of diagenetic events in the Zechstein Ca2 within the PB. Events are coloured based on their implications on reservoir quality (green = positive, red = negative, grey = neutral). Burial depths and temperatures are based on results by Schwarzer and Littke (2007) for the PB.

\subsubsection{Dolomitisation during shallow burial}

The replacement of the $\mathrm{Ca} 2$ mudstone to form DM1 was the earliest major diagenetic process after the sediment deposition at $\sim 250 \mathrm{Ma}$. A shallow burial dolomitisation process is supported by carbon and oxygen isotope data from $\mathrm{Ca} 2$ dolomites in NW Germany (Peryt and Magaritz, 1990; Below, 1992). Taking into account that the Ca2 mudstones were deposited in a rimmed platform environment (see Strohmenger et al., 1996), the likely dolomitisation mechanism responsible for the alteration of the original carbonates was seepage-reflux (Adams and Rhodes, 1960; Smith, 1980; Clark, 1981). The dissolution of dolomite probably created moldic and vuggy porosity (Biehl et al., 2016) shortly after dolomitisation during shallow burial (Schoenherr et al., 2018) and subsequently very early according to the paragenetic history. The formation of early vuggy porosity likely occurred at burial depths around $500 \mathrm{~m}$, based on the subsidence history of the PB and relative timing of dolomitisation. 


\subsubsection{Stylolitisation and calcitisation during intermediate burial}

Rapid subsidence during the Early Triassic promoted chemical compaction at intermediate burial depths around $800 \mathrm{~m}$ (Ali et al., 2010; Ebner et al., 2008) that facilitated the development of bedding-parallel stylolites. According to burial curves by Schwarzer and Littke (2007), the PB experienced rapid subsidence during the Early Triassic, of approximately $2,000 \mathrm{~m}$ in a $15 \mathrm{Ma}$ period, which is likely to have acted as a trigger for intensive bedding-parallel stylolitisation (see Paganoni et al., 2016). The presence of clay and organic matter in middle slope carbonate mudstones presumably also facilitated stylolitisation (e.g., Morad et al., 2018). DM1 can be found preserved between bedding-parallel stylolites, suggesting that the early stylolitisation events postdated dolomitisation of the Ca2 (Fig. 16). Calcitisation of the dolomite matrix started after some stylolitisation, as supported by: (i) the absence of calcitised dolomite preserved between stylolite teeth, and (ii) unevenly distributed insoluble stylolite material that is concentrated in dolomitic intervals. If calcitisation of the dolomite matrix had only occurred prior to stylolitisation, then no evidence of a dolomitic matrix should be preserved between stylolite teeth. Dolomitic matrix preserved between stylolite teeth was not observed in this study. However, patchy remnants of dolomitic matrix have been observed between stylolites elsewhere in the Ca2 by Schoenherr et al., (2018). Stylolites could alternatively have nucleated at layer interfaces (Sheppard, 2002) after calcitisation. This, however, would have caused insoluble stylolitic material to be evenly distributed between dolomite and calcitised dolomite on either side of the layer interface. Insoluble material appears instead disproportionately concentrated in dolomitic intervals (Figs. 11c, 14). Stylolites also preserve partially calcitised dolomite matrix, which suggests that further stylolitisation took place after calcitisation (Fig. 16b). This is further supported by observations from Schoenherr et al. (2018), where stylolites are found in calcitised dolomite and not exclusively dolomite-calcitised dolomite contacts, suggesting that stylolites also postdated calcitisation. Based on evidence from the present study, together with work by Schoenherr et al. (2018), stylolitisation was an ongoing process during calcitisation in the $\mathrm{Ca} 2$, facilitated by prolonged subsidence commencing in the Early Triassic. Bedding-parallel stylolitisation initiated in the Early Triassic, allowing stylolites to develop prior to calcitisation and continue to grow until inversion, helping to explain the variety of observed stylolitic interactions with dolomite and calcitised dolomite. Calcitisation fronts with preserved dolomite can also be observed that are unrelated to stylolitisation (Fig. 11b). Later calcitising events interacted with fractures to promote calcite vein cementation, with some fractures remaining open. Relationships between bedding-parallel stylolites and fracture veins (Table 2) suggest that both structures formed in multiple phases probably during pulses of subsidence.

Calcitising fluids entered the $\mathrm{Ca} 2$ using faults and fractures as major conduits, and subsequently invaded the dolomite matrix (Koehn et al., 2016b; Schoenherr et al., 2018). Seismic interpretation from the LSB by Biehl et al. (2016) identify faults cutting through A1 anhydrites related to the first Zechstein cycle and into the $\mathrm{Ca} 2$, indicating the potential for faults to act as conduits which is also likely to occur in the PB. Love et al. (1997) suggested that the extent of calcitisation was facies-independent and instead predominantly influenced by proximity to feeding faults. Due to the extensive calcitisation of the dolomite matrix observed in the studied wells and across the Ca2 slope deposits (Schoenherr et al., 2018), the source of the Ca-rich fluids are dominantly associated with pressure solution of the surrounding A1 and A2 anhydrite units (Hallenberger et al., 2018; Schoenherr et al., 2018). Calcitisation operates in a shallow burial diagenetic environment where fractures, which are 
acting as conduits for calcitising fluids, are equally of shallow burial (mesogenetic) origin as the basin continuously subsides.
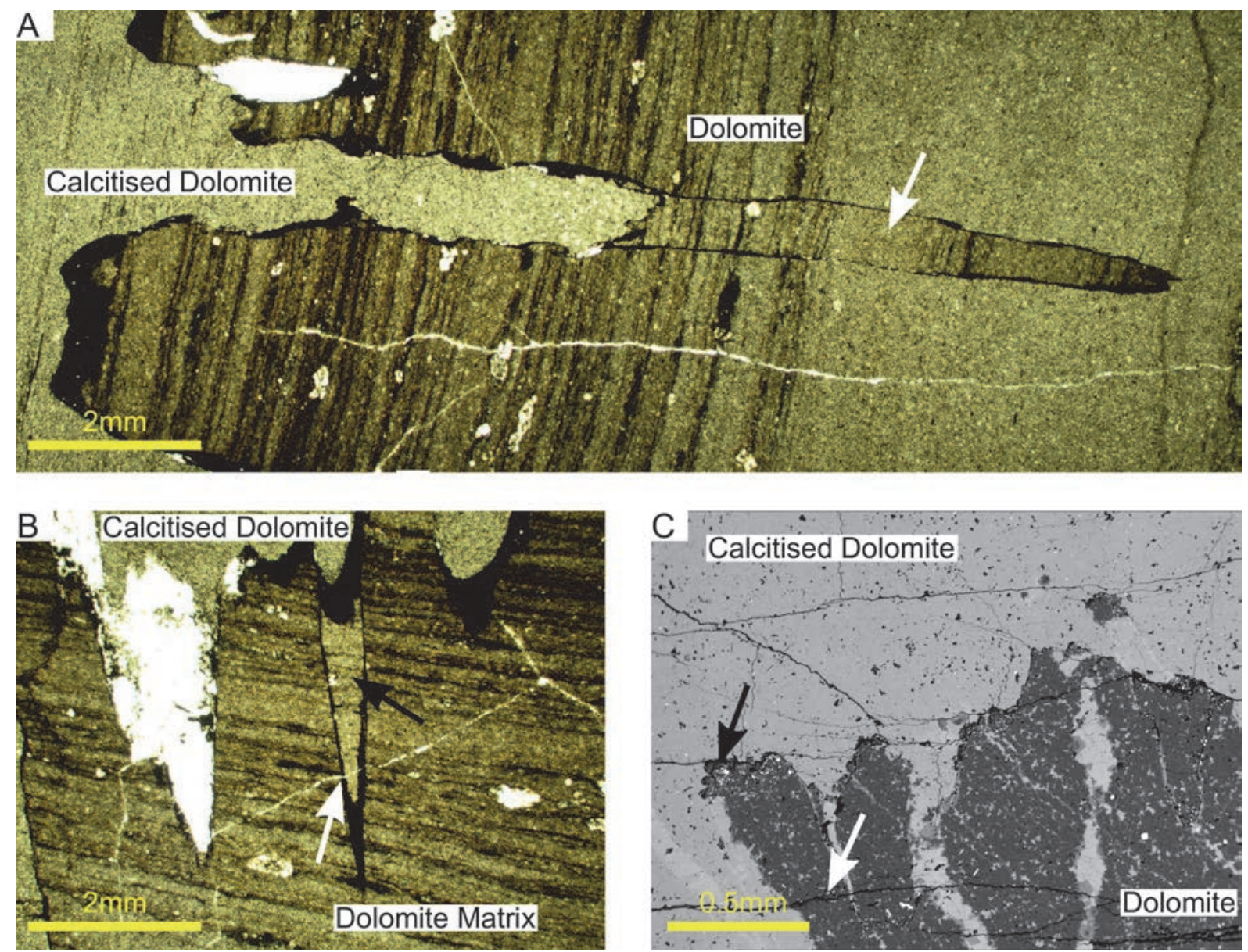

Figure 16. Thin section and SEM photographs identifying the relationship between matrix type and stylolites. A. Thin section photograph of a dolomite-calcitised dolomite front bound by stylolites, where the original dolomite matrix has been preserved between stylolite teeth (white arrow). B. Thin section photograph of a less dolomitised matrix (black arrow) bound between stylolite teeth, which has been post-dated by later vein emplacement (white arrow). C. SEM photograph of a dolomite-calcitised dolomite front bound by a stylolite (black arrow) alongside open fractures (white arrow).

\subsubsection{Tectonic stylolitisation and dolomite cementation}

Tectonic stylolites are found to cut bedding-parallel stylolites and vuggy and intermediate veins (Table 2). Tectonic stylolites require sub-horizontal compressive stress regimes (Ebner et al., 2010b) that were likely created during Late Cretaceous inversion (Schwarzer and Littke, 2007; Kley and Voigt, 2008). Salt tectonics in the Ca2 could also be responsible for the formation of tectonic stylolites, caused by fault reactivation during inversion. However, salt movement only occurred locally (Maystrenko et al, 2010).

Inversion led to a diverse range of fluids entering and interacting with the $\mathrm{Ca} 2$ beginning with ferroan dolomite that cemented some remaining open fractures. Most crystal cores are non-ferroan and surrounded by a ferroan exterior. Dolomite cementation is localised in veins and shows no evidence of interaction with the matrix. Fluids required a high concentration of $\mathrm{Fe}^{2+}$, estimated by Biehl et al. (2016) to be sourced from fluids which have migrated upwards through underlying clastic units such as the Rotliegend red beds. 


\subsubsection{Metal sulphides, siderite precipitation and anhydritisation}

Metal sulphides precipitating in the $\mathrm{Ca} 2$ include pyrite and sphalerite. Pyrite is likely to be associated with ferroan dolomite due to the presence of $\mathrm{Fe}^{2+}$-rich fluids rising into the $\mathrm{Ca} 2$. Metal sulphides are found to postdate most phases of calcite vein cementation and are found in higher abundances along stylolites and in close proximity to dolomitic intervals that feature relatively higher porosities as seen in MVT deposits elsewhere (Davies and Smith, 2006). Sphalerite is observed in lower abundance relative to pyrite. Biehl et al. (2016) suggest that elemental sulphur pore fillings, and therefore pyrite formation, in the LSB results from the interaction between $\mathrm{Fe}^{2+}$ and thermochemical sulphate reduction (TSR)-derived $\mathrm{H}_{2} \mathrm{~S}$. This is further supported by the $\mathrm{H}_{2} \mathrm{~S}$ content of reservoir gases in the Ca2 (Mittag-Brendel, 2000). Some minor pyrite observed in this study present a framboid texture, which is indicative of bacterial sulphate reduction (Sawlowicz, 2000) and commonly associated with euxinia on the Ca2 carbonate platform slope (Slowakiewicz et al., 2015). Siderite is found in minor abundances within the calcite matrix and is likely associated with the influx of metal sulphides and iron-rich fluids. Pyrite precipitation is common along well-developed stylolites indicating that stylolites were reopened and acted as conduits for diagenetic fluids at some stage (Carozzi and Von Bergen, 1987; Martín-Martín et al., 2017). Stylolite reactivation would have likely been facilitated by inversion processes during the Late Cretaceous (Schwarzer and Littke, 2007; Kley and Voigt, 2008).

\subsubsection{Late-stage stylolitisation and calcite cementation}

The resumption of burial that occurred during the Cenozoic (Petmecky et al., 1999; Schwarzer and Littke, 2007) is interpreted to have promoted (i) the late stage of chemical compaction and bedding-parallel stylolitisation, (ii) the late stage of calcite cementation, and (iii) the precipitation of several minor diagenetic phases including celestine and fluorite.

During the Cenozoic, subsidence rates were lower than in the Early Triassic (Schwarzer and Littke, 2007) and therefore not likely to have produced the same intensity of pressure solution. The extent of pressure solution may also have been reduced as the $\mathrm{Ca} 2$ had already undergone strong mechanical and chemical compaction. This is supported by cross-cutting relationships where only a minor quantity of bedding-parallel stylolites cross-cut, and therefore postdate, tectonic stylolites. Later bedding-parallel stylolites were most probably formed after inversion from the Middle Cretaceous to the present.

A final phase of calcite-rich fluids entered the $\mathrm{Ca} 2$ post inversion resulted in the cementation of open fractures to form calcite veins. Petrographic observations indicate that calcite cement post-dated stylolite reactivation as suggested by the lack of calcite filled stylolites.

Celestine infills vuggy pore space in the dolomite/calcite matrix and was likely associated with anhydrite units as a major source of Sr. Such fluids were likely saline basinal brines containing high amount of sulphate (Böttcher and Diezel, 2010), which is concordant with observed diagenetic products in this and previous studies (Biehl et al., 2016; Schoenherr et al., 2018). The gypsum-to-anhydrite dehydration reaction may have produced celestine as a by-product (Hanor, 2004), further supporting the timing relationship between celestine and anhydrite entering the $\mathrm{Ca} 2$. Fluorite is one of the last diagenetic phases to precipitate in the $\mathrm{Ca} 2$, indicating fluid cooling (Richardson and Holland, 1979), and is most probably associated with the uprising of heated hydrothermal brines (see Warren, 2016). Both Duschl 
et al. (2016) and Nadoll et al. (2018) use REE values from fluorite in the LSB to suggest that precipitation originated from remobilised basinal brines of sedimentary origin. This may suggest that lateral fluid flow has also occurred from basinal sediments in the PB, likely between anhydrite layers, to supply late-stage sources of fluorite and celestine.

\subsection{Structural trends in the Pompeckj Block}

Structural data from drill core measurements shows that vuggy and intermediate veins are typically found at shallower well depths on the slope, where calcitising fluids flow downwards from surrounding anhydrite layers (Schoenherr et al., 2018). Increasing effective stress from burial promotes a higher density of horizontal stylolites. However, this is based on the assumption that porosity in the host rock is occluded by cements in order to facilitate dissolution. Cross-cutting relationships between bedding-parallel stylolites and veins indicate multiple episodes of stylolitisation and vein emplacement, which is attributed to result from an extensional regime with high rates of subsidence like that of the Early Triassic (Schwarzer and Littke, 2007).

Vein abundance shows a negative correlation with stylolites at depth and can be related to lithological variations (Fig. 7). Core observations indicate that the distribution of veins is closely associated with lithology (i.e., dolomite vs. calcite), where the frequency of calcitised dolomite intervals with depth causes an increase vein abundance. This causes a change in the distribution of veins, suggesting that lithology is a controlling factor on structural distribution (Fig. 7). Calcitised dolomite intervals have more veins since the conversion from dolomite to calcitised dolomite causes a $75 \%$ reduction in compressive strength (Williams and McNamara, 1992). Therefore, rheological differences in competency promoted fracturing, brecciation and cementation.

Fractures are mainly cut by bedding-parallel stylolites and rarely cut by tectonic stylolites, indicating that the extensional stress promoting fracturing was higher during the Triassic Jurassic compared to subsidence in the Mid Cretaceous-Cenozoic. Open fractures are preserved in the $\mathrm{Ca} 2$ and are assumed to have a distribution similar to that recorded by fracture vein abundances. Open fractures significantly enhance reservoir permeability. Tectonic stylolites are found in low abundances throughout the studied core, potentially due to a reduced likelihood of being encountered by vertical wells, and formed during a changing stress regime caused by inversion in the Late Cretaceous as shown from $\mathrm{Ca} 2$ burial curves by Schwarzer and Littke (2007), or potentially by the localised reactivation of salt during inversion (Maystrenko et al., 2010). Tectonic stylolites predominantly cross-cut beddingparallel stylolites, suggesting that post-inversion tectonic stylolitisation in the Late Cretaceous and Cenozoic was of minor importance.

\subsection{Impact of stylolite networks}

Stylolite spacing measurements have a log-normal distribution (Fig. 9) which suggests that nucleation follows a non-linear trend influenced by solubility variations to promote pinning, as shown by Ebner et al. (2009). Removing under-sampled values causes a distribution change where spacing measurements are represented by an exponential fit. This is supported by Vandeginste and John (2013), who identified stylolite spacings to have an exponential distribution, suggesting that stylolites are randomly arranged and not self-organised as previously thought by Merino (1992). 
Stylolite amplitude measurements from the $\mathrm{Ca} 2$ are represented by a log-normal distribution which indicates the non-linear growth of stylolite teeth previously suggested by Koehn et al. (2007) and Peacock and Azzam (2006). When smaller under-sampled values are removed from the dataset the distribution changes to an exponential fit. This suggests that a distribution change occurs as stylolites progressively increase in amplitude, where a lognormal fit changes to an exponential fit with increasing amplitude. This change in amplitude behaviour is concordant with additional stylolite measurements collected from the $\mathrm{Ca} 2$ by Koehn et al. (2016a), and further supports the two-stage roughness regime proposed by Koehn et al. (2007). Both spacing and amplitude distributions subsequently change once under sampled values are removed, indicating how the inability to sample small-scale stylolite measurements may result in distribution changes being due to resolution limitations and therefore not representative of stylolite behaviour.

Stylolite sealing capacity is controlled by their morphology as teeth flanks are less inclined to act as barriers (Koehn and Beaudoin, 2017) (Fig. 5). According to Koehn et al. (2016a), rectangular layer and suture and sharp-peak stylolite types have sealing capacities that are controlled by the proportion of teeth flanks, determined by the frequency of stylolite teeth. Alternatively, seismogram pinning type stylolites have minimal teeth yet show sealing capacities similar to those of suture and sharp-peak type stylolites. This indicates that stylolite amplitude is also a key morphological factor influencing sealing capacity. Morphology is the controlling factor for sealing capacity affecting the amplitude and frequency of teeth, and both are influenced by the host rock lithology (Koehn et al., 2016a). Koehn et al. (2012) suggest that rock heterogeneity controls the 'pinning' of stylolite teeth to control amplitudes. Quantifying sealing capacity provides an insight into how diagenetic fluids interact with stylolites. In the analysed samples the sealing capacities of stylolite classes are: $67 \%$ for rectangular layer, $68 \%$ for seismogram pinning, $63 \%$ for suture and sharp-peak, and $89 \%$ for wave-like type stylolites. The estimation of stylolite sealing capacity in our samples demonstrates that wave-like type stylolites are the most effective barriers and inhibit vertical fluid migration. None of the observed stylolite morphologies had a $100 \%$ sealing capacity, indicating that stylolites were not entirely barriers to fluid flow and that calcitising fluids would have been able to partially infiltrate and replace the dolomitic matrix. Our results show that bedding-parallel stylolites are the most abundant type of stylolite in the Ca2 and formed during two phases of subsidence. Subsidence rates were higher during initial extension (Schwarzer and Littke, 2007) and therefore likely to be responsible for the majority of stylolitisation. Moreover, at that time sediments had a higher potential for compaction. Crosscutting relationships indicate that vuggy and intermediate veins are intersected by beddingparallel stylolites, implying that stylolites were dissolving the rock at different times.

Petrographic observations from thin section and SEM data suggest that stylolites acted as partial barriers to fluid flow during calcitisation in the Early Triassic $(\sim 240 \mathrm{Ma})$, creating vertical diagenetic stratification. However, petrographic observations also reveal that stylolites acted as conduits for diagenetic fluids (e.g., those precipitating metal sulphides in our case), and thus encompassing the two main end members of stylolite behaviour outlined by Carozzi and Von Bergen (1987). Therefore, the presence of calcitised dolomite-dolomite interlayering is partially influenced by stylolites in a way that they latter affect vertical fluid migration, and thus enhance bed parallel diagenetic alterations. In this regard, Gomez-Rivas et al. (2015) and Martín-Martín et al. (2017) concluded that stylolites can act as barriers to vertical flow of diagenetic fluids, and thus influence the spatial and petrophysical properties of altered rock. The lateral extent of diagenetic fluid propagation is controlled by the sealing capacity of stylolites and fluid pressure gradients. Reduced sealing capacities on stylolite 
teeth flanks allow leakage and the precipitation of minerals (Fig. 17). Subsequent sealing and inhibition of vertical fluid migration is therefore able to preserve the previously dolomitised matrix and influence the spatial distribution of diagenetic products. Whilst our findings support work by Ehrenberg et al. (2016) regarding the role of stylolites as permeability barriers, the scale of our observations and limited lateral extent of drill core do not allow evaluating whether stylolites form laterally continuous barriers and should therefore be considered as local permeability baffles instead.
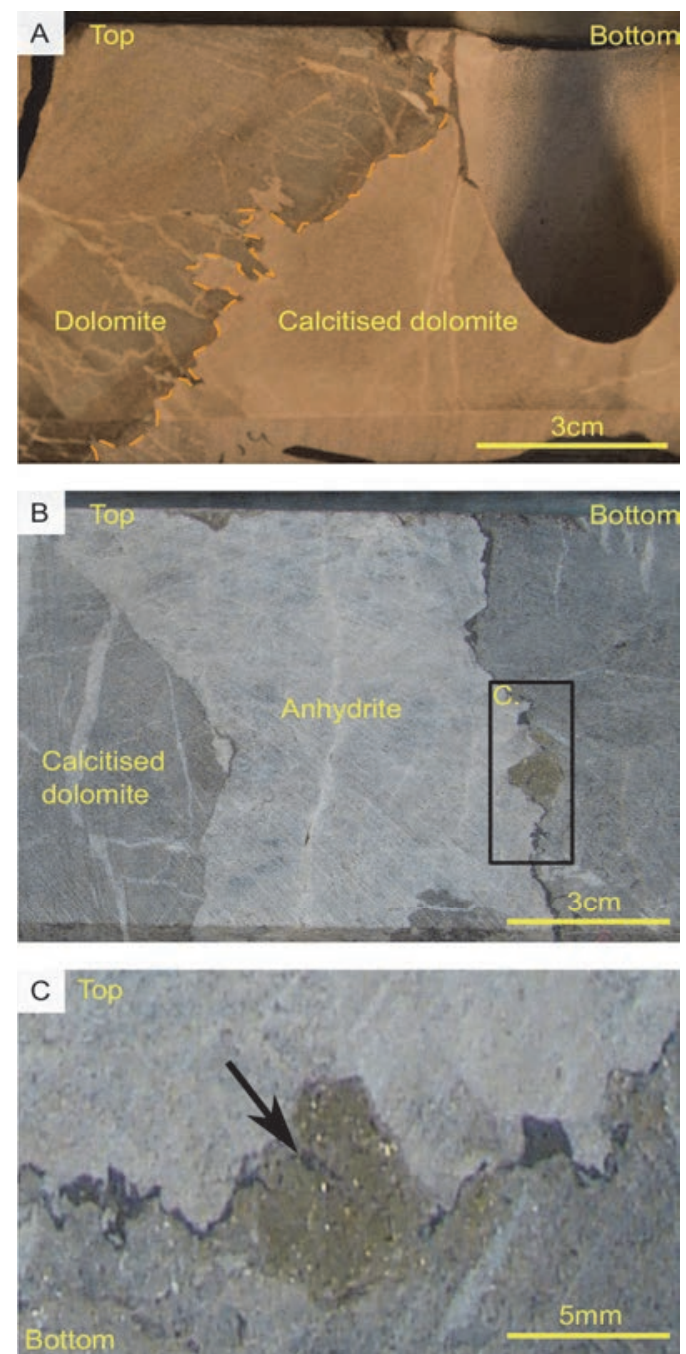

Figure 17. Core photographs indicating interactions between stylolites and paleofluids. A. Stylolite bound dolomite-calcitised dolomite front with partial leakage. B. Pyrite precipitation around a stylolite within partially calcitised dolomite. C. Detailed view of stylolite-pyrite relationship.

Pyrite was deposited in stylolites during intermediate burial and inversion when burial temperatures were suited to thermochemical sulphate reduction (Biehl et al., 2016), indicating that stylolites can additionally behave as conduits to fluid flow (Dawson, 1988; Braithwaite, 1989). Horizontal stylolites were reopened during inversion in the Late Cretaceous to act as conduits for Fe-rich fluids (Fig. 18). Stylolite reactivation did not coincide with periods of calcitisation since no calcite has precipitated within stylolites. Reactivation was initiated by a changing tectonic regime (in accordance with Kley and Voigt, 2008) due to Late Cretaceous inversion, which could have been further affected by localised salt movement (Maystrenko et al., 2010), indicating an important impact on reservoir quality development of the PB. 
A. Stylolitisation after dolomitisation

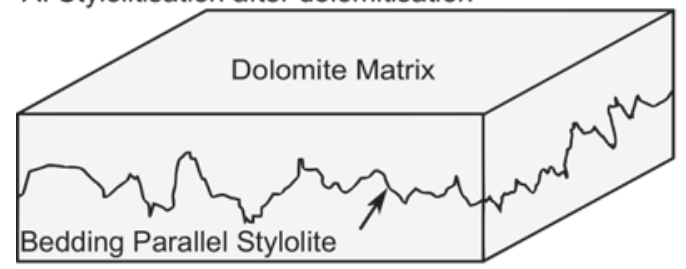

B. Calcitisation

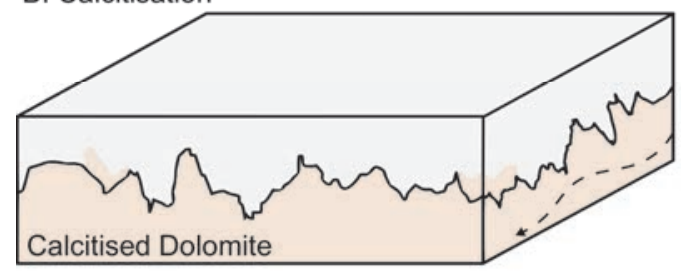

C. Stylolite Reopening

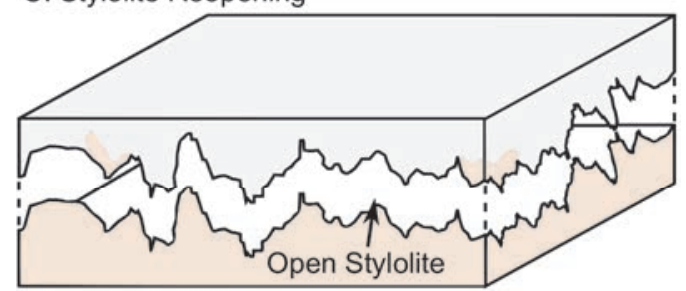

D. Stylolites as conduits

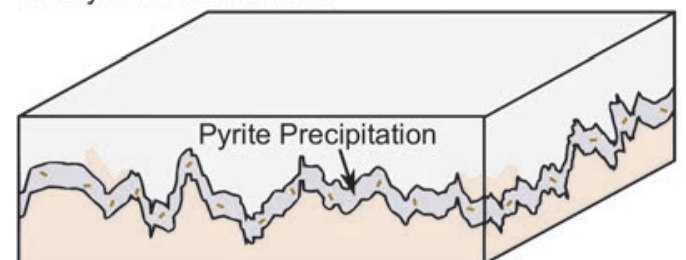

Figure 18. Block diagrams indicating the changing role of stylolites observed in the PB. A. Stylolites are created in a dolomite matrix (dark grey) prior to calcitisation. B. Stylolites act as barriers to partially inhibit the vertical migration of calcitising fluid to create horizontal calcitised dolomite layers and patchy calcitised dolomite around stylolites (light grey). C. Stylolites are reopened during inversion, postdating calcitisation therefore not acting as a conduit for calcitised dolomite. D. Reopened stylolites act as conduits for iron rich fluids which precipitate metal sulphides such as pyrite and galena (gold).

\subsection{Reservoir Quality}

The geodynamic evolution of the Southern Permian Basin, which includes the PB and the northern LSB, controlled the diagenesis of the $\mathrm{Ca} 2$ unit and produced spatial variations in lithology. Dolomitic layers represent the highest matrix reservoir quality intervals according to core plug porosity-permeability data from platform carbonates in the nearby LSB by Biehl et al., 2016, which is concordant with observations from other studies (Strohmenger et al., 1996; Schoenherr et al., 2014). Work by Schoenherr et al. (2018) across the whole Zechstein fairway emphasises the challenges associated with predicting the distribution of dolomitic intervals, which are found to be preserved in platform and upper slope carbonates away from extensive calcitisation on the lower slope deposits. In the case of our studied wells in the PB, stylolites act as partial barriers to affect vertical fluid migration, creating vertical diagenetic stratification within dolostone intervals (Fig. 19) and between dolomite-calcitised dolomite layers, with intervals varying between $3 \mathrm{~cm}$ to $>1 \mathrm{~m}$. In addition, dolomite-calcitised dolomite layers can be observed without the presence of stylolites, that Schoenherr et al. (2018) identify as slope soft-sediment structures. This suggests some additional depositional heterogeneity on the spatial distribution of reservoir quality within the $\mathrm{Ca} 2$ prior to 
stylolitisation, potentially due to the distribution of intercrystalline porosity in dolostone as suggested by Slowakiewicz et al. (2016). Calcitising fluids invaded the dolomitised rock and laterally migrated to create calcitised dolomite layering. As stylolites have been found to act as both partial barriers and conduits to fluid flow, their effects on reservoir quality heterogeneity are also dependent on the timing of other diagenetic events.

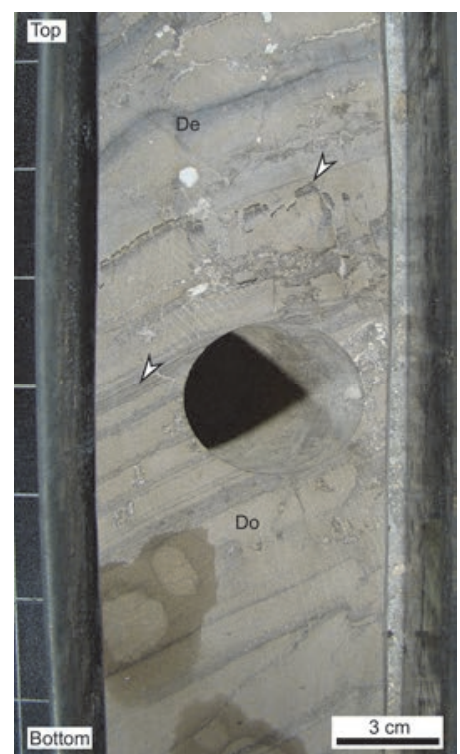

Figure 19. Core photograph showing dolomite (Do) and calcitised dolomite (De) vertically stratified by bedding parallel stylolites (white arrows).

The impact of stylolitisation on reservoir quality of the $\mathrm{Ca} 2$ carbonate is analogous, in terms of macrofabric distribution and influence on paleofluid flow, to many carbonate reservoirs in the Middle East. The Bab field (Abu Dhabi) features three intervals of stylolite networks that have influenced both reservoir quality and petroleum migration (Koepnick, 1988). Specifically, porosity reduction and reservoir thinning are positively correlated with stylolite abundance, whilst particular stylolitised layers create significant barriers to fluid flow. Despite stylolite formation postdating most diagenetic processes and hydrocarbon entrapment in the Bab Field (Koepnick, 1988), this reservoir still highlights the importance of understanding when stylolitisation occurred relative to the paragenetic history of the host rock. This point can be linked to the $\mathrm{Ca} 2$ in respect to understanding the timing of stylolitisation relative to calcitisation, and its subsequent impacts on the distribution of reservoir quality. Paganoni et al. (2016) evaluated stylolite networks and their influence on fluid flow in the Karaib Fm in Abu Dhabi, finding that stylolites can behave as both barriers and conduits to fluid flow. Stylolites act as present-day barriers to vertical fluid flow, however bitumen staining and secondary oil inclusions suggest that stylolites were reopened during compression and acted as conduits for migrating hydrocarbons Paganoni et al. (2016). The changing influence of stylolites on fluid flow as a result of regional tectonics in the Karaib Fm is comparable with stylolites observed in the Ca2, further supporting the idea that stylolites can be both barriers and conduits.

Stylolitisation can act as a major control on the spatial distribution of reservoir quality, where stylolite behaviour can dynamically change between partial barriers and conduits to fluid flow as a function of tectonic evolution. The changing role of stylolites must be closely observed in relation to the paragenetic evolution of platform carbonates in order to better understand stylolite-associated variations in reservoir quality, both spatially and temporally. 


\section{Conclusions}

Observations from the Zechstein $\mathrm{Ca} 2$ unit indicate a dynamic relationship between structural and diagenetic features on the spatial distribution of petrophysical properties, subsequently impacting reservoir quality. Structural logs show weak negative correlations between veins and stylolite abundance, controlled by lithological variations and pressure gradients. Tectonic stylolites postdate bedding-parallel stylolites and are rarely cut by veins. Cross-cutting relationships suggest that bedding-parallel stylolitisation emplacement both pre and postdates calcitisation and occurred at similar times to fracture cementation. Beddingparallel stylolitisation happened during rapid subsidence in different extensional events, whereas tectonic stylolites developed during the Late Cretaceous inversion. Stylolite spacing follows an exponential distribution, whereas teeth amplitude fits a power-law distribution. Suture and sharp-peak type stylolites have the lowest sealing capacity whereas wave-like type stylolites predominantly acted as barriers to fluid flow. The sealing capacity is controlled by stylolite morphology which is affected by host rock heterogeneities. Stylolite teeth amplitude and frequency affect the degree of leakage of calcitising fluids into dolomitic layers. Stylolites in mudstones acted as barriers to control the reaction front of calcitising fluid, causing vertical diagenetic stratification. Stylolites continued to grow after calcitisation and were later reopened during inversion in the Late Cretaceous to act as conduits for pyritising fluids.

The changing role of stylolites as conduits or barriers to fluid flow strongly influenced both petroleum and diagenetic alteration pathways, subsequently altering the spatial and temporal quality of slope carbonates. Stylolitisation provides an added degree of complexity when determining carbonate reservoir development strategies, signifying the importance of characterising these sub-seismic-scale structures and their impacts on fluid flow.

\section{Acknowledgements}

This study was developed within the framework of DGMK (German Society for Petroleum and Coal Science and Technology) project 718, funded by the companies ExxonMobil Production Deutschland GmbH, GDF SUEZ E\&P Deutschland GmbH, RWE Dea AG, and Wintershall Holding GmbH. The authors would like to acknowledge ExxonMobil Production Deutschland $\mathrm{GmbH}$ that kindly provided core data. Elliot Humphrey thanks the Natural Environment Research Council (NERC) Centre for Doctoral Training (CDT) in Oil \& Gas for a PhD grant. EGR acknowledges AGAUR (Agència de Gestió d'Ajuts Universitaris i de Recerca) for a "Beatriu de Pinós" research project. Additional funding was provided by the Generalitat de Catalunya Government (2017SGR-824) and the Spanish Government (projects CGL2015-66335-C2-1-R, CGL2015-69805-P and PGC2018093903-B-C22). We acknowledge Theresa Straub and Simon Gast for their assistance during core data collection. We would like to thank Miroslaw (Mirek) Slowakiewicz and an anonymous reviewer for their critical and constructive comments, together with the editorial guidance of Edoardo Perri.

\section{References}

Adams, J.E. and Rhodes, M.L., 1960. Dolomitization by seepage refluxion. AAPG Bulletin 44(12), 1912-1920. 
Agar, S.M. and Geiger, S., 2015. Fundamental controls on fluid flow in carbonates: current workflows to emerging technologies. Geological Society of London Special Publication 406, 1-59.

Al-Amrie, O.Y., Ben-Saad, M.A., Al Marzouqi, K.I., Kshirsagar, A.H. and Coskun, S.B., 2012. The Use of Formation Tester to Characterize the Permeability and Vertical Communication across the Stylolite Zones in Carbonate Reservoir. In: Abu Dhabi International Petroleum Conference and Exhibition. Society of Petroleum Engineers.

Alyan, M., Martin, J. and Irwin, D., 2015. November. Field Development Plan Optimization for Tight Carbonate Reservoirs. In Abu Dhabi International Petroleum Exhibition and Conference. Society of Petroleum Engineers.

Ali, S.A., Clark, W.J., Moore, W.R. and Dribus, J.R., 2010. Diagenesis and reservoir quality. Oilfield Review 22(2), 14-27.

Baldschuhn, R., Best, G. and Kockel, F., 1991. Inversion tectonics in the north-west German basin. Generation, accumulation and production of Europe's hydrocarbons. European Association of Petroleum Geoscientists 1, 149-159.

Baron, M. and Parnell, J., 2007. Relationships between stylolites and cementation in sandstone reservoirs: Examples from the North Sea, UK and East Greenland. Sedimentary Geology 194(1), 17-35.

Baud, P., Heap, M.J., Reuschlé, T. and Meredith, P.G., 2014. The Impact of Stylolites on Fluid Flow and Rheology of Porous Carbonates. In 76th EAGE Conference and Exhibition 2014.

Bäuerle, G., Bornemann, O., Mauthe, F. and Michalzik, D., 2000. Origin of stylolites in Upper Permian Zechstein anhydrite (Gorleben salt dome, Germany). Journal of Sedimentary Research 70(3), 726-737.

Becker, I., Koehrer, B., Waldvogel, M., Jelinek, W. and Hilgers, C., 2018. Comparing fracture statistics from outcrop and reservoir data using conventional manual and t-LiDAR derived scanlines in $\mathrm{Ca} 2$ carbonates from the Southern Permian Basin, Germany. Marine and Petroleum Geology 95, 228-245.

Becker, I., Müller, B., Koehrer, B., Jelinek, W. and Hilgers, C., 2019. Present-day stress control on fluid migration pathways: Case study of the Zechstein fractured carbonates, NW-Germany. Marine and Petroleum Geology 103, 320-330.

Below, A., 1992. Fazies und geochemische Diagenese Studie im Zechstein 2-Karbonat (Ca2) Nordwestdeutschlands. Reports Geologisch-Palaontologisches Institut Universitat Kiel, 60, $147 \mathrm{pp}$.

Ben-Itzhak, L.L., Aharonov, E., Karcz, Z., Kaduri, M. and Toussaint, R., 2014. Sedimentary stylolite networks and connectivity in limestone: Large-scale field observations and implications for structure evolution. Journal of Structural Geology 63, 106-123.

Betz, D., Führer, F., Greiner, G. and Plein, E., 1987. Evolution of the Lower Saxony basin. Tectonophysics 137(1), 127-170.

Biehl, B.C., Reuning, L., Schoenherr, J., Lüders, V. and Kukla, P.A., 2016. Impacts of hydrothermal dolomitization and thermochemical sulfate reduction on secondary porosity creation in deeply buried carbonates: A case study from the Lower Saxony Basin, northwest Germany. AAPG Bulletin 100(4), 597-621.

Böttcher, M.E. and Dietzel, M., 2010. Metal-ion partitioning during low-temperature precipitation and dissolution of anhydrous carbonates and sulphates. European Mineralogical Union Notes in Mineralogy 49, 139-187.

Braithwaite, C.J.R., 1989. Stylolites as open fluid conduits. Marine and Petroleum Geology 6(1), 93-96. 
Bruna, P.O., Lavenu, A.P., Matonti, C. and Bertotti, G., 2018. Are stylolites fluid-flow efficient features? Journal of Structural Geology, in press.

Bruns, B., Di Primio, R., Berner, U. and Littke, R., 2013. Petroleum system evolution in the inverted Lower Saxony Basin, northwest Germany: a 3D basin modeling study. Geofluids 13(2), 246-271.

Burgess, C.J. and Peter, C.K., 1985. January. Formation, distribution, and prediction of stylolites as permeability barriers in the Thamama Group, Abu Dhabi. In Middle East Oil Technical Conference and Exhibition. Society of Petroleum Engineers.

Carozzi, A.V. and Von Bergen, D., 1987. Stylolitic porosity in carbonates: a critical factor for deep hydrocarbon production. Journal of Petroleum Geology 10(3), 267-282.

Choquette, P.W. and Pray, L.C., 1970. Geologic nomenclature and classification of porosity in sedimentary carbonates. AAPG bulletin 54(2), 207-250.

Clark, D.N., 1980. The diagenesis of Zechstein carbonate sediments. Contributions to Sedimentology 9, 167-203.

Davies, G.R. and Smith Jr, L.B., 2006. Structurally controlled hydrothermal dolomite reservoir facies: An overview. AAPG bulletin 90(11), 1641-1690.

Dawson, W.C., 1988. Stylolite porosity in carbonate reservoirs. AAPG Search and Discovery Article \#91030.

Duschl, F., van den Kerkhof, A., Sosa, G., Leiss, B., Wiegand, B., Vollbrecht, A. and Sauter, M., 2016. Fluid inclusion and microfabric studies on Zechstein carbonates (Ca2) and related fracture mineralizations-New insights on gas migration in the Lower Saxony Basin (Germany). Marine and Petroleum Geology 77, 300-322.

Ebner, M., Koehn, D., Toussaint, R., Renard, F., 2009. The influence of rock heterogeneity on the scaling properties of simulated and natural stylolites. Journal of Structural Geology 31(1), 72-82.

Ebner, M., Koehn, D., Toussaint, R., Renard, F., Schmittbuhl, J., 2008. Stress sensitivity of stylolite morphology. Earth Planet. Sci. Lett. 277, 394e398.

Ebner, M., Piazolo, S., Renard, F. and Koehn, D., 2010a. Stylolite interfaces and surrounding matrix material: Nature and role of heterogeneities in roughness and microstructural development. Journal of Structural Geology 32(8), 1070-1084.

Ebner, M., Toussaint, R., Schmittbuhl, J., Koehn, D. and Bons, P., 2010b. Anisotropic scaling of tectonic stylolites: A fossilized signature of the stress field? Journal of Geophysical Research: Solid Earth 115(B6).

Ehrenberg, S., 2018. Petrophysical Heterogeneity in a Lower Cretaceous Limestone Reservoir, Onshore Abu Dhabi, United Arab Emirates. In 80th EAGE Conference and Exhibition 2018.

Ehrenberg, S.N., 2004. Factors controlling porosity in Upper Carboniferous-Lower Permian carbonate strata of the Barents Sea. AAPG bulletin 88(12), 1653-1676.

Ehrenberg, S.N., Eberli, G.P., Keramati, M. and Moallemi, S.A., 2006. Porosity-permeability relationships in interlayered limestone-dolostone reservoirs. AAPG Bulletin 90(1), 91-114.

Ehrenberg, S.N., Morad, S., Yaxin, L. and Chen, R., 2016. Stylolites and Porosity In A Lower Cretaceous Limestone Reservoir, Onshore Abu Dhabi, UAE. Journal of Sedimentary Research 86(10), 1228-1247.

Gale, J.F., Laubach, S.E., Olson, J.E. and Marrett, R., 2005. Using the link between diagenesis and fracturing to accurately predict, characterize, and model fluid-flow in fractured carbonate rocks. In SPE Latin American and Caribbean Petroleum Engineering Conference. Society of Petroleum Engineers. 
Gast, S., 2014. Investigation of structures of the Stassfurt carbonates in the Lower Saxony Zechstein. MSc thesis. Eberhard-Karls-Universität-Tübingen. Published in: http://www.geo.uni-tuebingen.de/studium/studentische-projekte/wissenschaftlichespraesentieren-ss-2014-und-ws-201415/geowissenschaften/simon-gast.html

Giorgioni, M., Iannace, A., D'Amore, M., Dati, F., Galluccio, L., Guerriero, V., Mazzoli, S., Parente, M., Strauss, C. and Vitale, S., 2016. Impact of early dolomitization on multi-scale petrophysical heterogeneities and fracture intensity of low-porosity platform carbonates (Albian-Cenomanian, southern Apennines, Italy). Marine and Petroleum Geology 73, 462478.

Gomez-Rivas, E., Martín-Martín, J.D., Bons, P.D. and Koehn, D., 2015. Can stylolite networks control the geometry of hydrothermal alterations? Geotectonic Research 97, 3436.

Hammes, U., Krause, M. and Mutti, M., 2013. Unconventional reservoir potential of the upper Permian Zechstein Group: a slope to basin sequence stratigraphic and sedimentological evaluation of carbonates and organic-rich mudrocks, Northern Germany. Environmental Earth Sciences 70(8), 3797-3816.

Hanor, J.S., 2004. A model for the origin of large carbonate-and evaporite-hosted celestine (SrSO4) deposits. Journal of Sedimentary Research 74(2), 168-175.

Hassan, T.H. and Wada, Y., 1981. Geology and development of Thamama zone 4, Zakum field. Journal of Petroleum Technology 33(07), 1-327.

Hallenberger, M., Reuning, L. and Schoenherr, J., 2018. Dedolomitization Potential of Fluids from Gypsum-to-Anhydrite Conversion: Mass Balance Constraints from the Late Permian Zechstein-2-Carbonates in NW Germany. Geofluids 2018, 1784821. doi.org/10.1155/2018/1784821.

Heap, M.J., Baud, P., Reuschlé, T. and Meredith, P.G., 2014. Stylolites in limestones: Barriers to fluid flow? Geology 42(1), 51-54.

Heap, M., Reuschlé, T., Baud, P., Renard, F. and Iezzi, G., 2018. The permeability of stylolite-bearing limestone. Journal of Structural Geology 116, 81-93.

Karnin, W.D., Rockenbauch, K. and Ruijtenberg, P.A., 1992. The effect of the succes of 3D seismic data on the exploration and appraisal of Zechstein targets in NW Germany. First Break 10(6), 233-240.

Kley, J. and Voigt, T., 2008. Late Cretaceous intraplate thrusting in central Europe: Effect of Africa-Iberia-Europe convergence, not Alpine collision. Geology 36(11), 839-842.

Koehn, D. and Beaudoin, N., 2017. Compaction and local fluid flow variations estimate through a new stylolite classification. Geophysical Research Abstracts 19, 9185.

Koehn, D., Ebner, M., Renard, F., Toussaint, R. and Passchier, C.W., 2012. Modelling of stylolite geometries and stress scaling. Earth and Planetary Science Letters 341, 104-113.

Koehn, D., Renard, F., Toussaint, R. and Passchier, C.W., 2007. Growth of stylolite teeth patterns depending on normal stress and finite compaction. Earth and Planetary Science Letters 257(3), 582-595.

Koehn, D., Rood, M.P., Beaudoin, N., Chung, P., Bons, P.D. and Gomez-Rivas, E., 2016a. A new stylolite classification scheme to estimate compaction and local permeability variations. Sedimentary Geology 346, 60-71.

Koehn, D., Urai, J., Virgo, S., Arndt, M., Abe, A., Enzmann, F., Schwarz, J.-O., Varga-Vass, A., Pataki-Rood, M., Blum, P., Kling, T., Bons, P., Sachau, T., and Gomez-Rivas, E., 2016b. DGMK-Forschungsbericht 718-2, Mineral Vein Dynamics Modelling (FRACS II). DGMK, Deutsche Wissenschaftliche Gesellschaftfür Erdöl, Erdgas und Kohle e.V., $240 \mathrm{pp}$. 
Koepnick, R.B., 1988. Significance of Stylolite Development in Hydrocarbon Reservoirs with an Emphasis on the Lower Cretaceous of the Middle East. Geological Society of Malaysia Bulletin 22, 23-43.

Laubach, S.E., Eichhubl, P., Hilgers, C. and Lander, R.H., 2010. Structural diagenesis. Journal of Structural Geology 32(12), 1866-1872.

Leyrer, K., Strohmenger, C., Rockenbauch, K. and Bechstaedt, T., 1999. High-resolution forward stratigraphic modeling of Ca2-carbonate platforms and off-platform highs (Upper Permian, Northern Germany). In: Computerized modeling of sedimentary systems, 307339. Springer, Berlin, Heidelberg.

Lohr, T., Krawczyk, C.M., Tanner, D.C., Samiee, R., Endres, H., Oncken, O., Trappe, H. and Kukla, P.A., 2007. Strain partitioning due to salt: insights from interpretation of a 3D seismic data set in the NW German Basin. Basin Research 19(4), 579-597.

Love, K.M., C. Strohmenger, Woronow, A., and Rockenbauch, K., 1997. Predicting Reservoir Quality Using Linear Regression Models and Neural Networks. In J.A. Kupecz, J. Gluyas, and S. Bloch, (eds.), Reservoir Quality Prediction in Sandstones and Carbonates: AAPG Memoir 69, 47-60.

Martín-Martín, J.D., Gomez-Rivas, E., Gómez-Gras, D., Travé, A., Ameneiro, R., Koehn, D. and Bons, P.D., 2017. Activation of stylolites as conduits for overpressured fluid flow in dolomitized platform carbonates. Geological Society of London Special Publication 459(1), 157-176.

Mazur, S. and Scheck-Wenderoth, M., 2005. Constraints on the tectonic evolution of the Central European Basin System revealed by seismic reflection profiles from Northern Germany. Netherlands Journal of Geosciences 84(4), 389-401.

Maystrenko, Y., Bayer, U., Brink, H.J. and Littke, R., 2008. The Central European basin system-an overview. In: Dynamics of complex intracontinental basins, 16-34. Springer, Berlin, Heidelberg.

Maystrenko, Y., Bayer, U., Scheck-Wenderoth, M. and Littke, R., 2010. Salt movements within the Central European basin system. Erdöl Erdgas Kohle 126(4), 156-163.

Merino, E., 1992. Self-organization in stylolites. American Scientist 80(5), 466-473.

Mittag-Brendel, E., 2000. Schwefelwasserstoffgenese in den Zechstein-Erdgaslagerstätten NW Deutschlands. Diss. BEB, Hannover: Universität Hannover.

Morad, D., Nader, F.H., Morad, S., Al Darmaki, F., and Hellevang, H., 2018. Impact of Stylolitization On Fluid Flow and Diagenesis in Foreland Basins: Evidence from an Upper Jurassic Carbonate Gas Reservoir, Abu Dhabi, United Arab Emirates. Journal of Sedimentary Research 88 (12): 1345-1361.

Nadoll, P., Rehm, M., Duschl, F., Klemd, R., Kraemer, D. and Sośnicka, M., 2018. REY and Trace Element Chemistry of Fluorite from Post-Variscan Hydrothermal Veins in Paleozoic Units of the North German Basin. Geosciences 8(8), 283.

Nelson, R.A., 1981. Significance of fracture sets associated with stylolite zones: geologic notes. AAPG Bulletin 65(11), 2417-2425.

Ortega, O.J., Gale, J.F. and Marrett, R., 2010. Quantifying diagenetic and stratigraphic controls on fracture intensity in platform carbonates: An example from the Sierra Madre Oriental, northeast Mexico. Journal of Structural Geology 32(12), 1943-1959.

Paganoni, M., Al Harthi, A., Morad, D., Morad, S., Ceriani, A., Mansurbeg, H., Al Suwaidi, A., Al-Aasm, I.S., Ehrenberg, S.N. and Sirat, M., 2016. Impact of stylolitisation on diagenesis of a Lower Cretaceous carbonate reservoir from a giant oilfield, Abu Dhabi, United Arab Emirates. Sedimentary Geology 335, 70-92. 
Peacock, D.C.P. and Azzam, I.N., 2006. Development and scaling relationships of a stylolite population. Journal of Structural Geology 28(10), 1883-1889.

Peryt, T. and Magaritz, M., 1990. Genesis of evaporite-associated platform dolomites: case study of the Main Dolomite (Zechstein, Upper Permian), Leba elevation, northern Poland. Sedimentology 37(4), 745-761.

Petmecky, S., Meier, L., Reiser, H. and Littke, R., 1999. High thermal maturity in the Lower Saxony Basin: intrusion or deep burial?. Tectonophysics 304(4), 317-344.

Reijers, T.J.A., 2012. Sedimentology and diagenesis as 'hydrocarbon exploration tools' in the Late Permian Zechstein-2 Carbonate Member (NE Netherlands). Geologos 18(3), 163 195.

Richter-Bernburg, G., 1955. Der Zechstein zwischen Harz und Rheinischen Schiefergebirge. Z. Dtsch. Geol. Ges 105, 876-899.

Richardson, C.K. and Holland, H.D., 1979. Fluorite deposition in hydrothermal systems. Geochimica et Cosmochimica Acta 43(8), 1327-1335.

Sawłowicz, Z., 2000. Framboids: from their origin to application. Prace mineralogiczne, Vol 88, 80 pp. Wydawnictwo Oddziału Polskiej Akademii Nauk.

Scheck-Wenderoth, M., Krzywiec, P., Zühlke, R., Maystrenko, Y., Froitzheim, N, 2008. Permian to Cretaceous tectonics of Central Europe. - In: McCann, T. (Ed.), The Geology of Central Europe, vol. 2. Mesozoic and Cenozoic, Geological Society Publishing House, 999-1030.

Schoenherr, J., Reuning, L., Hallenberger, M., Lüders, V., Lemmens, L., Biehl, B.C., Lewin, A., Leupold, M., Wimmers, K. and Strohmenger, C.J., 2018. Dedolomitization: Review and case study of uncommon mesogenetic formation conditions. Earth-Science Reviews $185,780-805$.

Schoenherr, J., Reuning, L., Wimmers, K., Fellmin, S., Smodej, J., Kuske, S., Brauckmann, F.J., Corona, F.V., Strohmenger, C.J., Guidry, S., 2014. The Impact of Dedolomitization on Reservoir Quality of the Upper Permian Zechstein-2-Carbonate, NW Germany. AAPG Search and Discovery Article \#51010. Houston, Texas.

Schwarzer, D. and Littke, R., 2007. Petroleum generation and migration in the 'Tight Gas' area of the German Rotliegend natural gas play: a basin modelling study. Petroleum Geoscience 13(1), 37-62.

Sheppard, T.H., 2002. Stylolite development at sites of primary and diagenetic fabric contrast within the Sutton Stone (Lower Lias), Ogmore-by-Sea, Glamorgan, UK. Proceedings of the Geologists' Association 113(2), 97-109.

Słowakiewicz, M., Perri, E. and Tucker, M.E., 2016. Micro-and nanopores in tight Zechstein 2 carbonate facies from the Southern Permian Basin, NW Europe. Journal of Petroleum Geology 39(2), 149-168.

Słowakiewicz, M., Tucker, M.E., Perri, E. and Pancost, R.D., 2015. Nearshore euxinia in the photic zone of an ancient sea. Palaeogeography, Palaeoclimatology, Palaeoecology 426, 242-259.

Smith, D.B., 1981. The Magnesian Limestone Upper Permian Reef Complex of Northeastern England. SEPM Special Publication 30, 161-186.

Strohmenger, C., Antonini, M., Jager, G., Rockenbauch, K. and Strauss, C., 1996. Zechstein 2 carbonate reservoir facies distribution in relation to Zechstein sequence stratigraphy (Upper Permian, Northwest Germany): an integrated approach. Bulletin des Centres de Recherches Exploration-Production Elf Aquitaine 20(1), 1-35. 
Strohmenger, C. and Strauss, C., 1996. Sedimentology and palynofacies of the Zechstein 2 Carbonate (Upper Permian, Northwest Germany): implications for sequence stratigraphic subdivision. Sedimentary Geology 102(1-2), 55-77.

Sweeney, R.E. and Kaplan, I.R., 1973. Pyrite framboid formation; laboratory synthesis and marine sediments. Economic Geology 68(5), 618-634.

Terzaghi , R. D., 1965. Sources of error in joint surveys. Geotechnique 13, 287- 304.

Toussaint, R., Aharonov, E., Koehn, D., Gratier, J.P., Ebner, M., Baud, P., Rolland, A. and Renard, F., 2018. Stylolites: A review. Journal of Structural Geology 114, 163-195.

Vandeginste, V. and John, C.M., 2013. Diagenetic implications of stylolitisation in pelagic carbonates, Canterbury Basin, Offshore New Zealand. Journal of Sedimentary Research 83(3), 226-240.

Warren, J.K., 2000. Dolomite: occurrence, evolution and economically important associations. Earth-Science Reviews 52(1), 1-81.

Warren, J.K., 2016. Evaporites: A geological compendium. Springer, 1813 pp.

Williams, D.M. and McNamara, K., 1992. Limestone to dolomite to calcitised dolomite conversion and its effect on rock strength: a case study. Quarterly Journal of Engineering Geology and Hydrogeology 25(2), 131-135.

Zeeb, C., Gomez-Rivas, E., Bons, P.D. and Blum, P., 2013. Evaluation of sampling methods for fracture network characterization using outcrops. AAPG Bulletin 97(9), 1545-1566. 